\title{
FUZZY-EXPERT SYSTEM FOR VOLTAGE STABILITY MONITORING AND CONTROL
}

CENTRE FOR NEWFOUNDLAND STUDIES

TOTAL OF 10 PAGES ONLY MAY BE XEROXED

(Without Author's Permission) 



National Library

of Canada

Acquisitions and Bibliographic Services

395 Wellington Street

Ottawa ON K1A ON4

Canada
Bibliothèque nationale

du Canada

Acquisitions ef services bibliographiques

395. rue Wellington

Ottawa ON KIA ONA

Canada
The author has granted a nonexclusive licence allowing the National Library of Canada to reproduce, loan, distribute or sell copies of this thesis in microform, paper or electronic formats.

The author retains ownership of the copyright in this thesis. Neither the thesis nor substantial extracts from it may be printed or otherwise reproduced without the author's permission.
L'auteur a accordé une licence non exclusive permettant à la Bibliothèque nationale du Canada de reproduire, prêter, distribuer ou vendre des copies de cette thèse sous la forme de microfiche/film, de reproduction sur papier ou sur format électronique.

L'auteur conserve la propriété du droit d'auteur qui protège cette thèse. $\mathrm{Ni}$ la thèse ni des extraits substantiels de celle-ci ne doivent être imprimés ou autrement reproduits sans son autorisation.

\section{Canadäa}




\begin{abstract}
In recent years, electric power utilities are forced to transmit maximum possible power through existing networks due to environmental, economic and regulatory changes. Due to these constraints, voltage instability has emerged as one of the most important areas of concern to modern power utilities. Voltage instability has been responsible for several system collapses in North America, Europe and Asia.
\end{abstract}

This thesis presents fundamental concepts of voltage stability. It describes three traditional voltage stability indices namely singular value decomposition, $\mathrm{L}$ index and QV curves. A simple five bus system is used to highlight the limitations of these traditional methods. A more widely accepted technique like modal analysis along with continuation power flow is studied and simulations are carried out on the IEEE 30 bus system and the New England 39 bus system. The test results clearly indicate areas prone to voltage instability and also identify groups of buses and critical bus that participate in the instability and thereby eliminate the problems associated with traditional methods. Hence, modal analysis technique is not only used as a benchmark tool for the development of the proposed fuzzyexpert system, but also as an important tool for validating its accuracy.

To understand this new approach, fundamental concepts of fuzzy logic based on the theory of approximate reasoning is dealt in detail. To get further insight into this alternate approach, a simple method using fuzzy sets for the voltage-reactive power control to improve the system voltage level is presented. A modified IEEE 30 bus system is used as an example to illustrate this method. Simulation results of this simple problem is encouraging and has been a useful starting point for the proposed fuzzy-expert system for voltage stability evaluation. 
The proposed fuzzy-expert system consists of two main components. The knowledge-base and the inference engine. Here, the key system variables like load bus voltage, generator MVAR reserve and generator terminal voltage which are used to monitor the voltage stability are stored in the database. Changes in the system operating conditions are reflected in the database. The above key variables are fuzzified using the theory of uncertainty. The rulebase comprises a set of production rules which form the basis for logical reasoning conducted by the inference engine. The production rules are expressed in the form of IF-THEN type, that relates key system variables to stability. The New England 39 bus system is taken as a case study to illustrate the proposed procedure. The expert system output is compared with the simulation results of a commercially available software ( VSTAB 4.1 ) output through modal analysis. The proposed system is fast and more efficient than conventional voltage stability methods. 


\section{Acknowledgments}

I would like to express my sincere gratitude and appreciation for the invaluable help and guidance given to me by Dr. Benjamin Jeyasurya during all stages of this work. My thanks are also to Dr. Jeyasurya, Faculty of Engineering and Applied Science and the School of Graduate Studies for the financial support provided to me during my M.Eng. program.

I acknowledge the assistance received from faculty members, fellow graduate students and other staff of the Faculty of Engineering and Applied Science.

Finally, I express my sincere gratitude to my family for their encouragement, support and understanding. 


\section{Contents}

$\begin{array}{lr}\text { Abstract } & \text { ii } \\ \text { Acknowledgments } & \text { iv } \\ \text { Contents } & \mathbf{v} \\ \text { List of Figures } & \text { viii } \\ \text { List of Tables } & \mathbf{x}\end{array}$

1 INTRODUCTION 1

2 VOLTAGE STABILITY ANALYSIS IN POWER 4 SYSTEMS

2.1 Introduction 4

2.2 Voltage Stability Phenomenon 5

2.3 Voltage Collapse Incidents 10

2.4 Factors Contributing to Voltage Instability/Collapse 11

2.5 Voltage Stability Analysis $\quad 12$

2.5.1 Singular value decomposition 13

2.5.2 $\mathrm{L}$ index 15

2.5.3 QV curves 17

2.6 Simulation Results and Discussions 19

2.6.1 Singular value decomposition 20

2.6.2 L index 22

2.6.3 QV curves 24

2.7 Limitation of Traditional Methods in Voltage Stability 28 Analysis

2.8 Need for Expert Systems in Electric Power System 29 
2.9 Summary

3 CONTINUATION POWER FLOW AND MODAL 31 ANALYSIS

3.1 Introduction

3.2 Continuation Power Flow Technique

3.2.1 Basic principle

3.2.2 Mathematical formulation

3.3 Modal Analysis

35

3.4 Simulation Results and Discussions 39

3.4.1 IEEE 30 bus system 40

3.4.2 New England 39 bus system 43

3.5 Summary 46

4 FUZZY-EXPERT SYSTEMS

4.1 Introduction 48

4.2 Expert System Structure 49

4.3 Theory of Approximate Reasoning 51

4.3.1 Fuzzy set theory 51

4.4 Application of Fuzzy-Set Theory to Power Systems 56

4.5 Summary 58

5 FUZZY CONTROL APPROACH TO VOLTAGE 60 PROFILE ENHANCEMENT FOR POWER SYSTEMS

S.1 Introduction 60

5.2 Problem Statement 61

5.3 Fuzzy Modeling 63

5.3.1 Bus voltage violation level 63

5.3.2 Controlling ability of controlling devices 64

5.3.3 Control strategy 64

5.4 Methodology 66 
5.5 Simulation Results and Discussions 66

$\begin{array}{lll}5.6 \text { Summary } & 71\end{array}$

6 FUZZY-EXPERT SYSTEM FOR VOLTAGE 72 STABILITY MONITORING AND CONTROL

6.1 Introduction 72

6.2 Expert System and Design $\quad 74$

6.2.1 The Database 75

6.2.2 The Rulebase 81

6.3 Inference Engine 83

6.4 Simulation Results and Discussions 84

6.5 Integration of Fuzzy-Expert Systern into an Energy 97 Management System

6.6 Summary 100

7 CONCLUSIONS 102

7.1 Contributions of the Research 102

7.2 Recommendations for Future Work 104

REFERENCES 105

APPENDICES

A Line and Bus data for the 5 bus system 110

B Rules relating key variables to stability measure of the 111 New England 39 bus system

C Data used for the rulebase formation for the 115 monitoring stage of the New England 39 bus system

D Complete list of expert system output for the 116 monitoring stage of the New England 39 bus system

E Participation factors for the critical case (at the 118 voltage stability limit ) of the New England 39 bus system 


\section{List of Figures}

2.1 Sample two bus power system 5

2.2 Voltage-Power characteristics for different $\mathrm{V} 1$ and power 6 factors

2.3 Radial system with some of the elements that play key role in 8 the voltage stability

2.4 Line model for two bus system 16

2.5 Sample QV curve 18

2.6 Single line diagram of the 5 bus system 19

2.7 Singular value decomposition for 5 bus system 21

2.8 L index of individual load buses for 5 bus system 22

2.9 System $L$ Index for 5 bus system 23

2.10 Family of QV curves for the base case of the 5 bus system 24

2.11 Family of QV curves near the stability limit of the 5 bus system 25

2.12 Family of QV curves at the collapse point of the 5 bus system 26

3.1 An illustration of the continuation power flow technique 33

3.2 Single line diagram of the IEEE 30 bus system 40

3.3 PV curve for bus 30 of the IEEE 30 bus system 41

3.4 Single line diagram of New England 39 bus system 44

3.5 PV curve for bus 12 of the New England 39 bus system 45

4.1 Expert system structure 49

4.2 Membership function for the fuzzy set TALL 52

4.3 The S-function 53

4.4 The II-function 54

5.1 Fuzzy model for bus voltage violation level 63

5.2 Fuzzy model of controlling ability of controlling device 64 
6.1 Membership function for the worst load bus voltage 76

6.2 Membership function for the worst MVAR reserve 77

6.3 Membership function of the generator terminal voltage 78 corresponding to the worst MVAR reserve

6.4 Voltage stability margin ( VSM ) for pre and post control cases 92

6.5 Fuzzy-expert system as a part of new EMS 98 


\section{List of Tables}

3.1 Five smallest eigenvalues for the three loading condition of the 42 IEEE 30 bus system

3.2 Participation factors for base case and critical case corresponding 42 to the least stable mode of the IEEE 30 bus system

3.3 Voltage stability margin for the three loading condition of the 43 IEEE 30 bus system

3.4 Five smallest eigenvalues for different loading conditions of the New England 39 bus system

3.5 Participation factors for critical case corresponding to the least stable mode of the New England 39 bus system

3.6 Voltage stability margin for the three loading condition of the New England 39 bus system

4.1 Fuzzy logic operators 55

5.1 Base case voltage profiles of the modified IEEE 30 bus system

5.2 Lower and upper limits of the controllers

5.3 Load bus voltage profiles of the modified IEEE 30 bus system before and after control actions

5.4 Optimal fuzzy control solution

6.1 Parameters " $\mathrm{a}$ " and " $\mathrm{A}$ " for the membership function of the key variables

6.2 Operating conditions for the 32 cases listed in Appendix D

6.3 Expert system output - Monitoring

6.4 Expert system output - control stage ( case A )

6.5 Expert system output - control stage ( case B )

6.6 Expert system output - control stage ( case C) 
6.7 Voltage stability margin ( VSM) for pre and post control cases 93

A1 Line data for the 5 bus system 110

A2 Bus data for the 5 bus system 110

B1 Rules relating worst load bus voltage to stability measure 111 under group 1

B2 Rules relating key generator MVAR reserve to stability measure 111 under group 2

B3 Rules relating key generator terminal voltage to stability measure 111 under group 3

B4 Rules relating combined key variables to stability measure 112 under group 4

Cl Data used for the rulebase formation 115

D1 Expert system output for various neighborhood points - 116 Monitoring stage

El Bus and Generator participation factors for critical case 118 


\section{Chapter 1}

\section{INTRODUCTION}

The phenomenon of voltage instability in electric power systems is characterized by a progressive decline of voltage, which can occur because of the inability of the power system to meet increasing demand for reactive power. The process of voltage instability is generally triggered by some form of disturbance or change in operating conditions that create increased demand for reactive power in excess of what the system is capable of supplying. The dynamic characteristics of loads, location of reactive compensation devices and other control actions such as those provided by load tap changing transformers, automatic voltage regulating equipment, speed governing mechanism on generators are important factors which affect voltage stability.

In recent years, electric power utilities are forced to transmit maximum possible power through existing networks due to environmental, economical and regulatory changes. As a result of load growth without a corresponding increase in either the generation or transmission capacity, many power systems operate close to their voltage stability boundaries. Many utilities around the world have experienced major black-outs caused by voltage instability.

When a power system is operating close to its limits, it is essential for the operators to have a clear knowledge of its operating state. A number of special algorithms and methods have been proposed in the literature for the analysis of voltage instability. But these traditional methods require 
significantly large computations and are not efficient enough for real-time use in energy management system. Hence, there is a need for an alternative approach, which can quickly detect potentially dangerous situation and alleviates the power system from possible collapse or blackout. To meet the above challenge, this thesis proposes a new and cost-effective solution based on furzy-expert system.

The aim of the thesis is as follows:

- To investigate three traditional methods of voltage stability indices with the help of a simple system. The three methods are singular value decomposition, $\mathrm{L}$ index and QV curves. The analysis of these methods will bring out the basic concepts involved in voltage stability along with their limitations.

- To apply modal analysis along with continuation power flow for voltage stability analysis of a power system. These methods aim to overcome the limitations of the traditional methods.

- To review expert systems and fuzzy logic concepts. This will lay a foundation for the understanding of the proposed fuzzy-expert system. To get further insight into this alternative approach, a simple method using fuzzy sets for voltage-reactive power control to improve the system voltage level is investigated.

- To design a fuzzy-expert system for voltage stability monitoring and control. The designed fuzzy-expert system is investigated and compared with modal analysis output. Extensive simulations are carried out to validate the usefulness of this new approach. 
The thesis is organized as follows. Chapter two reviews the concepts of voltage stability followed by the description of the three most widely used techniques for the analysis of voltage stability in power systems. A simple 5 bus system is used to highlight the limitations of these traditional methods. Chapter three gives a detailed description of modal analysis for voltage stability evaluation followed by the simulation results of the IEEE 30 bus system and the New England 39 bus system. This chapter forms the basis for the development of fuzzy-expert system. Chapter four presents the theory behind fuzzy-expert systems. In chapter five, a simple application of fuzzy logic to power system is shown to emphasize the theory developed in chapter four. A modified IEEE 30 bus system is used as an example to illustrate this method. Chapter six gives a detailed description of the fuzcy-expert system for voltage stability monitoring and control. The New England 39 bus system is taken as case study to illustrate the proposed procedure. It highlights the database and rulebase design. In the database design, the key system variables that are used to monitor the voltage stability are transformed into fuzzy domain to obtain their appropriate membership functions. The rulebase comprises a set of production rules that form the basis for logical reasoning conducted by the inference engine. These production rules relate key system variables to stability. To validate the proposed system, simulation results are compared with modal analysis output. Finally, chapter seven concludes the thesis with some recommendation for future work. 


\section{Chapter 2}

\section{VOLTAGE STABILITY ANALYSIS IN POWER SYSTEMS}

\subsection{Introduction}

Voltage control and stability problems are not new to the electric utility industry but are now receiving special attention. Maintaining an adequate voltage level is a major concern because many utilities are loading their bulk transmission networks to their maximum possible capacity to avoid the capital cost of building new lines and generation facilities. Load growth without a corresponding increase in transmission capacity has brought many power systems close to their voltage stability boundaries. In this context, the terms "voltage stability", "voltage collapse" occur frequently in the literature.

[EEE committee report [1] defines the following terminology related to voltage stability:

"Voltage Stability" is the ability of a system to maintain voltage so that when load admittance is increased, load power will increase and that both power and voltage are controllable.

"Voltage Collapse" is the process by which voltage instability leads to very low voltage profile in a significant part of the system.

"Voltage Instability" is the absence of voltage stability and results in progressive voltage decrease ( or increase). Voltage instability is a dynamic process. A power system is a dynamic system. In contrast to rotor angle stability, the dynamics mainly involve the loads and the means for voltage control. 
A system enters a state of voltage instability when a disturbance, increase in load, or system change causes voltage to drop quickly or drift downward and operators automatic system controls fail to halt the decay. The voltage decay may take just a few seconds or 10 to 20 minutes. If the decay continues unabated, steady-state angular instability or voltage collapse will occur.

\subsection{Voltage Stability Phenomenon [2]}

Voltage collapse is in general caused by either load variations or contingencies. The following illustration considers voltage collapse due to load variations. The basic configuration used to explain voltage collapse is shown in Fig. 2.1.

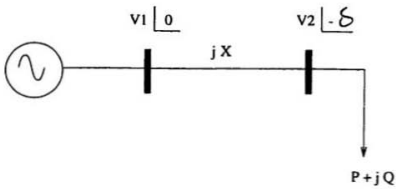

V2: receiving end load voltage $\quad X$ : reactance of the line

V1: sending end voltage $\delta$ : load angle

Fig.2.1 Sample two bus power system

In this circuit, a synchronous generator is connected to a load through a lossless transmission line. The load is described by its real and reactive 
powers $\mathrm{P}, \mathrm{Q}$ and the load voltage V2 [3]. The governing algebraic relations are

$$
\begin{aligned}
& \mathrm{P}=\frac{|\mathrm{V} 1||\mathrm{V} 2|}{\mathrm{X}} \sin \delta \\
& \mathrm{Q}=-\frac{|\mathrm{V} 2|^{2}}{\mathrm{X}}+\frac{|\mathrm{V} 1||\mathrm{V} 2|}{\mathrm{X}} \cos \delta
\end{aligned}
$$

Under steady-state conditions, equations (2.1) and (2.2) represent the voltage/power relation at the load end of the circuit.



Fig.2.2 Voltage-Power characteristics for different $\mathrm{V} 1$ and power factors [3] 
Fig. 2.2 shows the plot of load voltage versus real power for several power factors and different sending-end voltages. The graph of these equations is a parabola. In the region corresponding to the top half of the curves, the load voltage decreases as the receiving-end power increases. The nose points of these curves represents the maximum power that can theoretically be delivered to the load. If the load demand were to increase beyond the maximum transfer level, the amount of actual load which can be supplied as well as the receiving-end voltage will decrease. These curves indicate that there are two possible values of voltage for each loading. The system cannot be operated in the lower portion of the curve even though a mathematical solution exists. Consider an operating point in the lower portion of the curve. If an additional quantity of load is added under this condition, this added load will draw additional current from the system. The resulting drop in voltage in this operating state would more than offset the increase in current so that the net effect is a drop in delivered power. If the load attempts to restore the demanded power by some means, such as by increasing the current, the voltage will decrease even further and faster. The process will eventually lead to voltage collapse or avalanche, possibly leading to loss of synchronism of generating units and a major blackout.

In a larger system, apart from load dynamics, other dynamics such as generator excitation control, on load tap changer ( OLTCs), static var compensator ( SVC) controls, thermostat controlled loads, etc, play an important role in the voltage stability of the system. The radial system shown below presents a clear picture of the voltage stability problem and its associated dynamics [1]. 


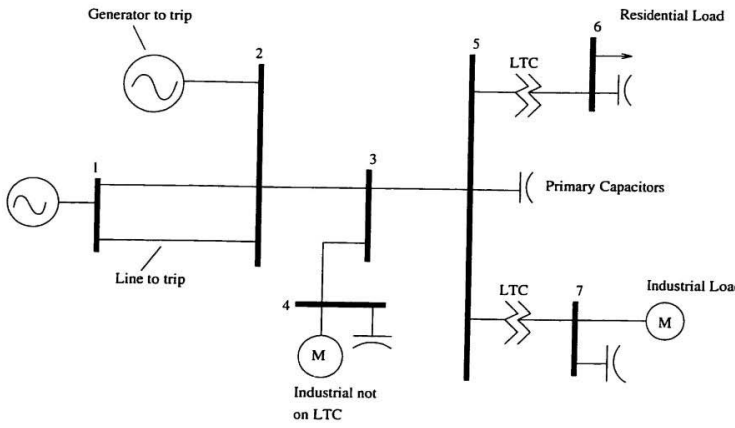

Fig.2.3 Radial system with some of the elements that play key role in the voltage stability [1]

In the above system, two types of loads are considered: residential and industrial. Residential load has a relatively high power factor and tends to drop with voltage. On the other hand, industrial load has low power factor 
and does not vary much with voltage. If this system is heavily loaded and operating near its voltage stability limit, a small increase in load (active or reactive ), a loss of generation or shunt compensation, a drop in sending end voltage can bring about voltage instability. Assuming that one of the above mentioned changes happen and receiving end voltage falls, several mechanisms come into play.

As residential loads are voltage dependent, the active and reactive load drops with drop in voltage, while industrial active and reactive loads which are dominated by induction motors change little. Thus, the overall effect may be the stabilization of voltage at a value slightly less than the rated value.

The next action is the operation of distribution transformer load tap changers ( LTCs ) to restore distribution voltages. The residential active load will increase while the industrial reactive load will decrease. The increasing residential load will initially outweigh the decrease in reactive load causing the primary voltage to fall further. In this scenario, the onload tap changers ( OLTCs ) may be close to their limits, primary voltage at around $90 \%$ and distribution voltage below normal.

Industrial loads served from the primary system without LTCs will be exposed to the reduced voltage levels. This greatly increases the stalling of induction motors. When a motor stalls, it will draw increasing reactive current, bringing down the voltage on the bus. This results in a cascade stalling of other induction motors resulting in a localized voltage collapse. Since, most large induction motors are controlled by magnetically held contactors, the voltage collapse would cause most motors to drop off from 
the system. This loss of load will cause the voltage to recover. However, the recovered voltage will again result in the contactor closing, motor stalling and another collapse. Thus, this loss and recovery of the load can cause alternate collapse and recovery of voltage.

From the above discussion, it is clear that voltage stability is essentially a slow dynamics and is affected by the nature and type of load and other control actions.

Power systems have become more complex and are being operated closer to their capability limits due to economic and environmental reasons. While these trends have contributed to angle instability, it is clear from a study of recent incidents of system failures [1,4] that, it is voltage instability that is the major factor in these failures.

\subsection{Voltage Collapse Incidents [4]}

Throughout the world, there have been disturbances involving voltage collapse over the last twenty years with the majority of these occurrences since 1982. Two typical examples of voltage collapse occurrences are the 1987 French and Tokyo power system failures.

In France on January 12, 1987 at 10:30 am, one hour before the incident occurred, the voltage level was normal despite very low temperature outside. For various reasons, three thermal units in one generating station failed in succession between 10:55 and 11:41 a.m. Thirteen seconds later, a fourth unit tripped as the result of operation of the maximum field current protection circuit. This sudden loss in generation led to a sharp voltage drop. This drop in voltage increased thirty seconds later and 
spread to adjacent areas, resulting in the tripping of other generating units on the system within a span of few minutes. As a result, $9000 \mathrm{MW}$ were lost on the French system between I1:45 and 11:50 am. Normal voltage levels were restored rapidly after some load shedding took place on the system.

In the same year on July 23, Tokyo's power system also experienced the voltage collapse phenomena. The temperature rose to $39^{\circ} \mathrm{C}$ and as a result, there was a sharp increase in the demand due to the extensive use of air-conditioners. The $500 \mathrm{KV}$ voltages began to sink ( to $460 \mathrm{KV}$ ) and eventually the over current protection on the $500 \mathrm{KV}$ lines operated. As a result, seven $500 \mathrm{KV}$ substations were without supply. This resulted in the loss of $8000 \mathrm{MW}$ of load for about three hours. It is interesting to note that during all this time, there was no indication or abnormal operation which would have alerted the operators to the impending disaster. The only indication that something out of the ordinary happening was that the rate of rise of the load was $400 \mathrm{MW} /$ minute, which was twice as much as ever recorded before.

\subsection{Factors Contributing to Voltage Instability/Collapse [5]}

Based on the voltage collapse incidents described in references 1 and 4, the voltage collapse can be characterized as follows:

The initiating event may be due to a variety of causes: small gradual changes such as natural increase in system load, or large sudden disturbances such as loss of a generating unit or a heavily loaded line. Sometimes, a seemingly uneventful initial disturbance may lead to successive events that eventually cause the system to collapse. 
The heart of the problem is the inability of the system to meet its reactive demands. Usually, but not always, voltage collapse involves system conditions with heavily loaded lines. When the transport of reactive power from neighboring areas is difficult, any change that calls for additional reactive power support may lead to voltage collapse.

The voltage collapse generally manifests itself as a slow decay of voltage. It is the result of an accumulative process involving the actions and interactions of many devices, controls and protective systems. The time frame of collapse in such cases could be of the order of several minutes. Thus, some of the major factors contributing to voltage instability can be summarized as follows:

- $\quad$ sudden increase in load.

- rapid on-load transformer tap changing.

- level of series and shunt compensation.

- reactive power capability of generators.

- $\quad$ response of various control systems.

\subsection{Voltage Stability Analysis}

As incidents of voltage instability become more common and systems continue to be loaded closer to their stability limits, it becomes imperative that system operators be provided with tools that can identify potentially dangerous situation leading to voltage collapse. A number of special algorithms have been proposed in the literature [6] for the analysis of voltage instability. Few of them are:

(1) Singular Value Decomposition.

(2) 'L' Index. 
(3) PV and QV curves.

(4) Eigenvalue Decomposition.

(5) V-Q Sensitivity.

(6) Energy Based Measure.

In this chapter, the first three methods are discussed in detail because they are commonly used in the electric power industry. While, singular value decomposition and ' $L$ ' Index provide the necessary analytical tools in identifying voltage collapse phenomena, $\mathrm{PV}$ and $\mathrm{QV}$ curves are the more traditional methods used as voltage collapse proximity indicators ( VCPI ) in industry today. PV curves have already been discussed with respect to the simple two bus power system in section 2.2 .

\subsubsection{Singular value decomposition}

In 1988, Tiranuchit and Thomas [7] proposed a global voltage stability index based on the minimum singular value of the Jacobian. They showed that a measure of the nearness of a matrix $A$ to singularity is its minimum singular value. An important aspect to be considered when deriving corrective control measure is the question " how close is the Jacobian to being singular?".

To examine the above question, consider the following basic problem: given a matrix $\mathrm{A}$, determine conditions on perturbation matrix $\mathrm{A}$ such that $A+\triangle A$ is singular. Note that if $A$ is non-singular, one may write

$$
A+\Delta A=\left(I+A^{-1} \Delta A\right) A
$$

The term $\left(I+A^{-1} \Delta A\right)$ can be shown to have an inverse if 
$\| A^{-1} \Delta A \mid<1$, which is guaranteed if $\|\Delta A\|<\frac{1}{\left\|A^{-1}\right\|}$. Hence, a measure of nearness of matrix $A$ to singularity is the number $\left\|A^{-1}\right\|^{-1}$.

To get a better understanding of the use of this voltage stability index, consider a set of non-linear algebraic equations in matrix format given by

$$
f(x)=\left[\begin{array}{c}
f_{1}(x) \\
f_{2}(x) \\
\\
f_{a}(x)
\end{array}\right]=y
$$

Given $y$ and $f(x)$, we want to solve for $x$. This can be done by NewtonRhapson iterative method, where old values of $x$ are used to generate new values of $x$ i.e.

$$
x(i+1)=x(i)+J^{-1}[y-f\{x(i)\}]
$$

where, $\mathrm{J}$ is an invertible matrix, called the Jacobian matrix.

The Newton-Raphson method can be applied to solve the load flow problem. The power flow equations in polar co-ordinates are as follows:

$\mathrm{P}_{\mathrm{K}}=\mathrm{V}_{\mathrm{K}} \cdot \sum_{\mathrm{n}=1}^{\mathrm{N}} \mathrm{Y}_{\mathrm{K} \mathrm{a}} \mathrm{V}_{\mathrm{n}} \cos \left(\theta_{\mathrm{Ka}}+\delta_{\mathrm{K}}-\delta_{\mathrm{n}}\right)$
$\mathrm{Q}_{\mathrm{K}}=\mathrm{V}_{\mathrm{K}} \cdot \sum_{\mathrm{n}=1}^{\mathrm{N}} \mathrm{Y}_{\mathrm{Ka}} \mathrm{V}_{\mathrm{n}} \sin \left(\theta_{\mathrm{K}_{\mathrm{a}}}+\delta_{\mathrm{K}}-\delta_{\mathrm{n}}\right)$

$P_{K}, Q_{K}$ : scheduled real and reactive power supplied to bus $K$

$\mathrm{V}_{\mathrm{K}}, \mathrm{V}_{\mathrm{a}}$ : bus voltages at bus $\mathrm{K}$ and $\mathrm{n}$

$\delta_{\mathrm{K}}, \delta_{\mathrm{n}}$ : phase angles of the bus voltages at bus $\mathrm{K}$ and $\mathrm{n}$

$\theta_{\mathrm{K}}$ : admittance angle

$\mathrm{Y}_{\mathrm{Ka}}$ : elements of the bus admittance matrix 
For the power flow problem

$$
\begin{gathered}
x=\left[\begin{array}{l}
\delta \\
V
\end{array}\right] \\
y=\left[\begin{array}{l}
P \\
Q
\end{array}\right] \\
f(x)=\left[\begin{array}{l}
P(x) \\
Q(x)
\end{array}\right]
\end{gathered}
$$

The Jacobian matrix for the power flow is of the form:

$$
J=\left[\begin{array}{ll}
\frac{\partial \mathrm{P}_{\mathrm{i}}}{\partial \delta_{i}} & \frac{\partial \mathrm{P}_{\mathrm{i}}}{\partial \mathrm{V}_{\mathrm{i}}} \\
\frac{\partial \mathrm{Q}_{\mathrm{i}}}{\partial \delta_{\mathrm{i}}} & \frac{\partial \mathrm{Q}_{\mathrm{i}}}{\partial \mathrm{V}_{\mathrm{i}}}
\end{array}\right]
$$

The inverse of the matrix $\mathrm{J}$ is given by

$$
\mathrm{J}^{-1}=\frac{1}{|\mathrm{~J}|} * \text { Adj J }
$$

If $|\mathrm{J}|=0$, then the Jacobian is non-invertible or singular. The singular value decomposition of the Jacobian matrix gives a measure of the system closeness to voltage collapse. As the power system moves towards voltage collapse, the minimum singular value of the Jacobian matrix approaches zero.

\subsection{2 $\mathrm{L}$ index}

In 1986, Kessel and Glavitsch [8] proposed a fast voltage stability indicator. This method provides a means to assess voltage stability without actually computing the operating point. Consider a two bus system as shown in Fig. 2,4. 


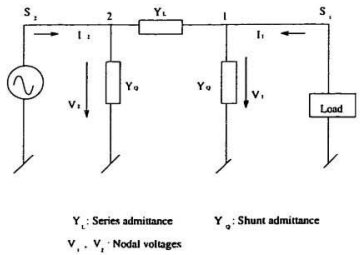

Fig. 2.4 Line model for two bus system

The properties of node 1 can be described in terms of the admittance matrix of the system.

$$
Y_{11} V_{1}+Y_{12} V_{2}=I_{1}=\frac{S_{1}^{*}}{V_{1}^{*}}
$$

$Y_{11}, Y_{12}, Y_{21}, Y_{22}$ form the admittance matrix $[Y]$ and $S_{1}$ is the complex power.

$$
\mathrm{S}_{1}=\mathrm{V}_{1} \mathrm{I}_{\mathrm{i}}
$$

Equation 2.13 can be written as

$$
\begin{array}{r}
V_{1}+\frac{Y_{12}}{Y_{11}} V_{2}=\frac{S_{1}^{*}}{Y_{11} V_{1}^{*}} \\
\text { or } \quad V_{1}^{2}+V_{0} V_{1}^{*}=\frac{s_{1}^{*}}{Y_{11}}
\end{array}
$$




$$
\text { where, } \quad V_{0}=\frac{Y_{12}}{Y_{11}} V_{2}=-\frac{Y_{L}}{Y_{L}+Y_{Q}} V_{2}
$$

It is shown in reference [8] that the solution of equation 2.15 indicates the stability limit of the power system. At this point

$$
\left|1+\frac{V_{0}}{V_{1}}\right|=\frac{S_{1}}{Y_{11} * V_{1}^{2}}=1
$$

This relation can be used to define an indicator $\mathrm{L}_{j}$ at each bus for the assessment of the voltage stability. It's range is $0 \leq \mathrm{Lj} \leq 1$.

The global indicator describing the stability of the complete system is the maximum of all $\mathrm{L}_{\mathrm{i}}$ values at each and every bus. The indicator $\mathrm{L}$, is a quantitative measure for the estimation of the distance of the actual state of the system to the stability limit. The local indicators $L_{j}$ can be used to determine the buses from which voltage collapse may originate.

\subsubsection{QV Curves [9]}

QV curves are presently the workhorse method of voltage stability analysis at many utilities. The QV curves show the sensitivity and variation of bus voltages with respect to reactive power injections. They are used for the assessment of the voltage stability of the system. They show the mega volt ampere reactive ( MVAR ) and voltage margins to instability and provide information on the effectiveness of reactive power sources in controlling the voltage in different parts of the system. 


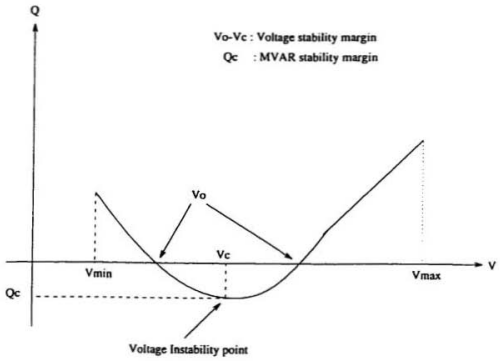

Fig.2.5 Sample QV curve

For each QV curve, a reactive power source is placed at the selected bus ( QV bus ) to move its voltage in a given range, $V_{\min }$ to $V_{\max }$, by a given step size $V_{\text {stop. }}$. At each voltage step, the power flow is solved to compute the required MVAR injection $\mathrm{Q}_{i}$, at the $\mathrm{QV}$ bus for holding its voltage at $\mathrm{V}_{i}$. The points of $\mathrm{QV}$ curves are computed by starting from the existing voltage, $V_{0}$ and zero MVAR injection and increasing the voltage until $V_{\max }$ is reached or the power flow fails to solve. Then the system is reset to the initial condition at $\mathrm{V}_{0}$ and the $\mathrm{QV}$ computation proceeds in the 
opposite direction by decreasing the voltage until $V_{\min }$ is reached or the power flow becomes unsolvable. Fig.2.5 shows a typical QV curve. The voltage difference $V_{0}-V_{c}$ and the value of $Q_{c}$ provides the voltage and MVAR stability margins at the bus and the slope of the curve provides the sensitivity information.

\subsection{Simulation Results and Discussions}

In this section, a simple 5 bus system is taken as a case study to verify the algorithms discussed in the previous sections. The single line diagram is shown in Fig.2.6 [10]. The line and bus data for the 5 bus system is shown in Appendix A. In this system, bus 1 is the reference ( slack ) bus while buses $2,3,4$ and 5 are considered load ( PQ ) buses. The test system is studied without considering any limit on the generators.

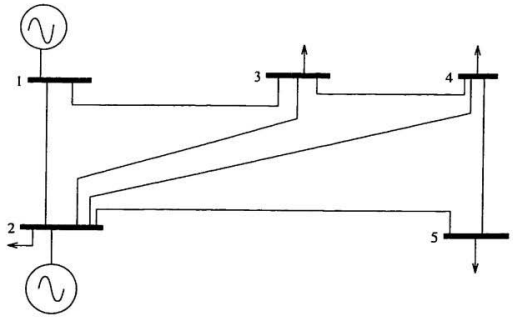

Fig.2.6 Single line diagram of the 5 bus system 
The system is driven from an initial operating point (base case) up to the collapse (bifurcation) point by changing the loading factor. Loading factor is a scalar parameter used to simulate the system load changes that drives the system from base case to the bifurcation point.

The term "bifurcation" [11] in power systems can be explained as follows: For a load condition, in addition to normal load-flow solution, which is typically the actual operating point or stable equilibrium point ( s.e.p ), several solutions may be found for the load-flow equations. The "closest" one to the s.e.p. is the unstable equilibrium point (u.e.p) of interest for voltage collapse studies [12]. These equilibrium points approach each other as the system is loaded, up to the point when only one solution exists. If the system is loaded further, all system equilibria disappear. The "last" equilibrium has been identified as the steady-state voltage collapse point. This point is known as saddle-node bifurcation point. At this bifurcation point, the real eigenvalue of the load-flow Jacobian becomes zero, that is., the Jacobian becomes singular.

\subsubsection{Singular value decomposition}

Simulation results of the singular value decomposition method for the 5 bus system is shown in Fig.2.7. In this method, the system could not be loaded beyond a loading factor of 3.3 because of the divergence of the load flow solution. Loading factor of 3.3 corresponds to a total load of 544.5 MW. 


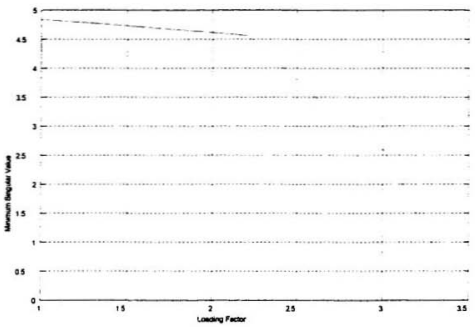

Fig.2.7 Singular value decomposition for 5 bus system

From Fig.2.7, it can be said that as the loading factor is increased from the base case, the minimum singular value decreases and finally approaches zero at the collapse point. For example, the minimum singular index is 0.8986 at a loading factor of 3.3 (near the stability limit ), very close to the collapse point. Hence, the minimum singular value gives a measure of the nearness to instability or in other words 'distance to collapse'. The system is said to have collapsed when the minimum singular value of the Jacobian is zero. It can be seen from the above figure that at or near the collapse point, the singular index is very sensitive to load changes and hence there is a sharp drop in its value. Thus, this index fails when the system is operating close to its limits. Another major disadvantage of this method, is the large computation time required to calculate the minimum singular value for larger systems. 


\subsubsection{Index}

Simulation results of the " $\mathrm{L}$ " index method for the 5 bus system is shown in Fig.2.8 and Fig.2.9.

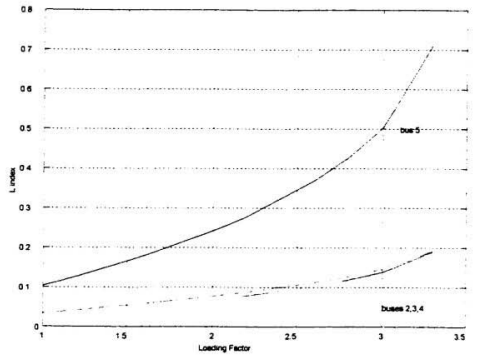

Fig.2.8 $\mathrm{L}$ index of individual load buses for 5 bus system 


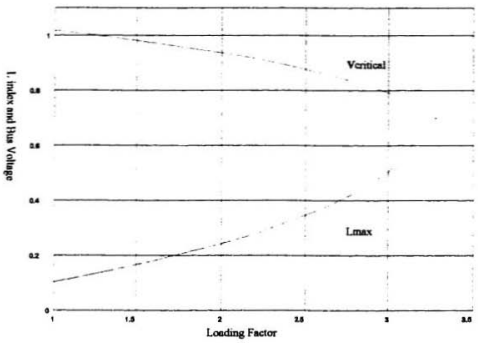

Fig.2.9 System L index for 5 bus system

From Fig.2.8, as the loading factor is increased, the $\mathrm{L}$ index of bus 5 approaches more rapidly towards unity than other buses. When the L index is unity, the system collapses. For instance, near the collapse point ( loading factor of 3.3 ), the $\mathrm{L}$ index of bus 5 is 0.7165 , while for buses 2,3 and 4 the $\mathrm{L}$ indices are $0.1927,0.1901,0.1926$ respectively. The maximum of these is 0.7165 . This represents the system $L$ index, which gives a quantitative measure for the estimation of the distance of the actual state of the system to the stability limit. Fig.2.9 shows the system L index and the corresponding bus voltage for the 5 bus system. The local $L$ index permits the determination of those buses from which collapse may originate. In the above simulation, voltage collapse originates from bus 5 . This is considered as the critical bus for this system. 
Thus, the stability indicator $\mathrm{L}$ is able to characterize the load flow solution and the potential of the system to become unstable. This is bound to the load flow model and the assumption of a PQ node. The model does not reflect any dynamic behavior. It is based on single node calculations and is therefore easy to calculate. However, it may require substantial engineering judgment in a large system.

\subsubsection{QV curves}

The family of QV curves for the three operating cases: basecase ( Load $=165 \mathrm{MW})$, near the stability limit ( Load $=565 \mathrm{MW}$ ), at the point of instability ( Load $=584.53 \mathrm{MW}$ ) are shown in Fig.2.10, Fig.2.11, Fig.2.12 respectively.

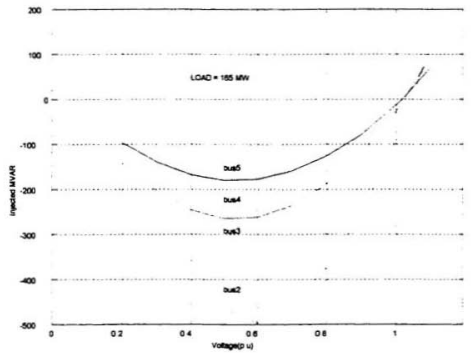

Fig.2.10 Family of QV curves for the base case of the 5 bus system 




Fig.2.11 Family of QV curves near the stability limit of the 5 bus system 


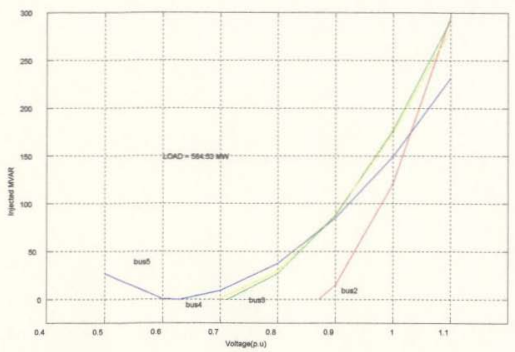

Fig.2.12 Family of QV curves at the collapse point of the 5 bus system

The above QV curves are obtained from a commercially available software VSTAB 4.1 [9]. In this program, lists of buses for which QV curves are to be generated and the span of each QV curve must be provided. The span of QV curve is specified by providing the maximum and minimum voltage level at a bus. The program is initiated by assigning the parameters QVCRVS $=1$ and SELQVC $=$ FALSE in the parameter file of the VSTAB program. For example, consider the base case operating condition of Fig.2.10. The lists of load buses for which QV curves are to be generated are 2,3,4 and 5. The span of each QV curve is specified by providing the maximum voltage level $\mathrm{V}_{\max }=1.1 \mathrm{p} . \mathrm{u}$. and minimum voltage level $\mathrm{V}_{\min }=0.2 \mathrm{p}$.u. The step voltage is 0.1 p.u. For the bus 2 , the base case voltage $V_{0}=1.0475$ p.u. For this bus, $Q V$ curves are generated by solving the series of power flow equations 2.6 and 2.7 until $\mathrm{V}_{\max }$ is reached. Then the system is reset to the initial condition at $V_{0}$ and the $Q V$ 
computation is carried out in the opposite direction by decreasing the voltage. Here, eventhough $V_{\text {min }}$ is assigned at 0.2 p.u, the power flow becomes unsolvable at 0.4 p.u. itself. Hence, computations are stopped at this value. Thus, the voltage stability margin $V_{o}-V_{c}=1.0475-0.6=$ 0.4475 p.u. and MVAR stability margin is -497.06 MVAR.

From the above results, the following interpretations can be made.

- At the base case operating point, all buses have significant reactive margin, while at the point of instability, the buses have virtually no reactive margin. The reactive margin is the MVAR distance from the operating point to the bottom of the curve.

- There is a significant voltage stability margin for the base case operating point compared to the margin at or near the stability limit. For example, corresponding to the most critical bus i.e. bus 5 , the voltage stability margin for the base case and near the stability limit is 0.518 p.u. and 0.1205 p.u respectively.

QV curves can thus be used in the assessment of voltage stability of the system. Another advantage of this method is the characteristics of test bus shunt reactive compensation can be plotted directly on the QV curve. The operating point is the intersection of the $\mathrm{QV}$ characteristic and the reactive compensation characteristic. This is useful since reactive compensation is often a solution to voltage stability problem. On the other hand, since the method artificially stresses a single bus, conclusions should be confirmed by more realistic methods. Also, the curves are obtained by a series of power flow simulations which makes it more time consuming. 


\subsection{Limitation of Traditional Methods in Voltage Stability Analysis}

The steady-state techniques described in the previous section have not found widespread practical applications due to the following shortcomings:

- they do not provide practical margins to measure the stability of the system.

- they provide little or no information regarding the mechanism of instability.

- they focus on the strength of individual buses and not from the system wide perspective.

- they make significant modeling assumptions such as constant generator voltages or constant impedance loads and such assumptions may eliminate factors which influence system stability.

From the analysis of the traditional methods, it can be concluded that the most important aspect of a practical voltage stability index is the computation effort and hence not useful for real-time use in energy management system ( EMS ). Moreover, these methods depend largely on conventional power flows to determine the voltage collapse levels of various points in a network. Furthermore, this approach is laborious, time consuming and requires analysis of massive amounts of data as the size of the power system increases. When the power system is operating close to its limits, it is essential for the operator to have a clear knowledge of the operating state of the power system. Thus, for on-line applications, there is a need for tools which can quickly detect the potentially dangerous situations of voltage instability and provide guidance to steer the system away from voltage collapse. Recently, efforts to improve the speed and 
ability to handle stressed power system have led to the development of intelligent systems.

\subsection{Need for Expert Systems in Electric Power System}

In recent years, research in the field of artificial intelligence ( AI ) has achieved significant success. Among the most significant of these is the development of "Expert" or "Knowledge-Based" systems and "Artificial Neural Networks ( ANNs )". Expert systems and ANNs are subsets of AL. Both these areas have attracted a widespread interest in the field of power system applications. Reference [13] presents a global view of knowledge engineering applications and tools available in the field of power systems.

Expert systems is a branch of AI that makes extensive use of specialized knowledge to solve problems at the level of a human expert. That is, an expert system is a computer system which emulates the decision-making ability of a human expert. It consists of two main components: knowledge-base and the inference engine. The expert systems will be treated in detail in chapter 4 .

Expert systems offer a number of advantages [14]:

- Assist Human Experts

An expert system can reduce tedious and redundant manual tasks and thereby enhance productivity leading to efficient operation.

- Flexibility

Each production rule represents a piece of knowledge relevant to the task. Hence it is very convenient to add, remove and modify a rule in the knowledge base as experience is gained.

- $\quad$ Rapidity 
The expert system can provide more rapid reaction to emergency events than human operators. This is very useful in power system operation.

In the power system area, expert system applications has been mainly devoted to power system operations [14]. This is because the operation of power systems has become very complex and operators are unable to deal with the large amount of data associated with the modern energy management system. Also, power system operation experience is lost when experienced operators retire or change jobs. It is important to preserve this valuable experience as it is not contained in any textbook or manual. Thus, expert systems can assist in decision-making and minimize errors by human operators.

\subsection{Summary}

In this chapter, the basic concepts, analytical tools and industry experience related to voltage stability analysis of power systems are reviewed. Advantages and disadvantages of the traditional methods are highlighted by simulating a simple 5 bus system. From the simulation results, it can be concluded that the existing methods require significantly large computations and are not useful for real-time use in energy management system. Hence, an alternate approach, such as the applications of artificial intelligent techniques to power systems in general is discussed.

To enhance the capabilities of the EMS, an integrated approach of knowledge-based systems ( artificial neural networks and expert systems ) and conventional power system solution methodologies has to be adopted. This approach has the potential to achieve secure and economic operation of the power system. 


\section{Chapter 3}

\section{CONTINUATION POWER FLOW AND MODAL ANALYSIS}

\subsection{Introduction}

With the growing concern for voltage instability in the power system industry, much attention has been given to investigating this phenomenon. As a result, a number of techniques have been developed to study the problem. However, well accepted criteria and study procedures regarding system voltage stability do not yet exist. Many utilities continue to use post-contingency voltage decline as an indicator of voltage stability, while some others use performance criteria based on either PV or QV curves. Thus, there is a need to develop a practical procedure which utilities can apply as part of their routine studies. Also, results of voltage stability analysis using power flow based static techniques need to be validated using detailed time-domain simulation tools, such as the TransientMidterm Stability Programs which are similar to EPRI's ETMSP [15].

Static analysis is based on the solution of conventional or modified power flow equations. A popular tool for static based voltage stability analysis is EPRI's voltage stability ( VSTAB ) program [9]. The VSTAB, developed by Ontario Hydro, is a voltage stability assessment package for large complex power systems. It provides information regarding both the proximity to and mechanisms of voltage instability. The main features of the VSTAB package are:

- Automatic modification of the system state which includes increasing the load in a predefined manner, creating new dispatches, performing sets of contingencies. 
- Comprehensive voltage stability analysis like PV curves, QV curves and modal analysis.

- Determination of Megawatt (MW ) or Megavar ( MVAR ) distance to voltage instability, which can indicate modes of instability characterized by groups of buses, branches and generators which participate in the instability.

- Capability to obtain the nose of the PV curves using the continuation power flow.

- Steady state approximations to time frames associated with ULTC action, governor response, Automatic Generator Control ( AGC ) action and economic dispatch.

Voltage stability analysis technique based on the eigen-analysis of the reduced steady state Jacobian matrix is referred to as modal analysis. It provides measures of proximity to instability and clearly indicates areas ( modes) which have potential stability problems. The modal analysis along with continuation power flow technique $[16,17]$ have been applied to voltage stability analysis of practical systems. In the following sections, these two techniques are discussed in detail, supplemented by the simulation results of typical test systems using VSTAB and EPRI's Interactive Power Flow ( IPFLOW ) [18] tools.

\subsection{Continuation Power Flow Technique}

A particular difficulty encountered in indices mentioned in section 2.5., is that the Jacobian of a Newton-Raphson power flow becomes singular at the voltage stability limit. Consequently, conventional power-flow algorithms are prone to convergence problems at operating conditions near the stability limit. The continuation power-flow analysis overcomes 
this problem by reformulating the power-flow equations so that they remain well-conditioned at all possible loading conditions.

\subsubsection{Basic principle}

This technique was proposed by Ajjarapu and Christy in 1992 [19]. The continuation power-flow analysis uses an iterative process involving a predictor-corrector scheme as shown in Fig.3.1.

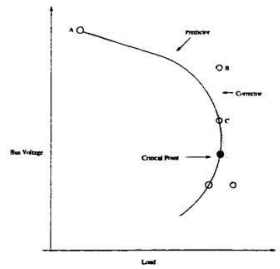

Fig.3.1 An illustration of the continuation power flow technique

From a known initial solution (A), a tangent predictor is used to estimate the solution (B) for a specified pattern of load increase. The corrector step then determines the exact solution $(C)$ using a conventional power-flow analysis with the system load assumed to be fixed.

\subsubsection{Mathematical formulation}

When the objective is to obtain the maximum loadability point of a system, the problem can be formulated as

$$
\mathrm{F}(\delta, v)=\lambda \mathrm{K}
$$


where, $\delta$ is the vector of bus voltage angles

$v$ is the vector of bus voltage magnitude

$\mathrm{K}$ is the vector representing percent load change at each bus

$\lambda$ is the load parameter

Equation 3.1 can be re-written as

$$
\mathrm{F}(\delta, v, \lambda)=0
$$

In the predictor step, a linear approximation is used to predict the next solution for a change in one of the state variables (i.e. $\delta, v, \lambda$ ). Taking the derivatives of both sides of the equation and evaluating the derivatives at the initial solution, will result in the following set of linear equations in matrix form:

$$
\left[\begin{array}{lll}
\mathrm{F}_{\delta} & \mathrm{F}_{v} & \mathrm{~F}_{\lambda}
\end{array}\right]\left[\begin{array}{l}
\mathrm{d} \delta \\
\mathrm{d} v \\
\mathrm{~d} \lambda
\end{array}\right]=[0]
$$

To account for one more equation due to the introduction of an additional variable in the power flow equations ( namely $\lambda$ ), one of the components of the tangent vector is set to +1 or -1 . This component is referred to as the continuation parameter. Equation 3.2 now becomes

$$
\left[\begin{array}{c}
\mathrm{F}_{d} \mathrm{~F}_{v} \mathrm{~F}_{\lambda} \\
\mathrm{e}_{\mathrm{k}}
\end{array}\right]\left[\begin{array}{l}
\mathrm{d} \delta \\
\mathrm{d} v \\
\mathrm{~d} \lambda
\end{array}\right]=\left[\begin{array}{c}
0 \\
\pm 1
\end{array}\right]
$$

where, $e_{k}$ is a vector where all the entries are zero, except for the variable which is chosen as the continuation parameter, where the entry is ' 1 '.

Initially, the continuation parameter is chosen as $\lambda$ (load parameter) and the sign of its slope is positive. However, once the tangent vector is found, the continuation parameter is selected as the bus voltage with the largest entry in the tangent vector and its sign is used during the next 
predictor step. Once the tangent vector is found, the next solution can be approximated as:

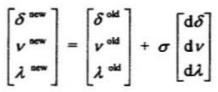

The step size $\sigma$ should be chosen so that a solution would exist for the specified continuation parameter. If for a given step size, a solution cannot be found in the corrector step, the step size should be reduced until a successful solution is obtained.

In the corrector step, the original set of equations $\mathrm{F}(\delta, v, \lambda)=0$ is augmented by one equation that specifies the value of the state variable selected as continuation parameter. The new set of equations can be written as

$$
\left[\begin{array}{c}
F \\
x_{k}-\eta
\end{array}\right]=[0]
$$

where $x_{\mathbf{k}}$ is the state variable that has been selected as the continuation parameter and $\eta$ is equal to $x^{\text {sex }}$. This set of equations is solved using Newton-Raphson power flow method. The introduction of the extra equation makes the Jacobian to be non-singular at the maximum loadability point and hence a solution can be obtained at that point.

\subsection{Modal Analysis [5]}

The Modal analysis for voltage stability is briefly discussed below.

Consider the linearized power flow equation expressed as 


$$
\left[\begin{array}{l}
\Delta \mathrm{P} \\
\Delta \mathrm{Q}
\end{array}\right]=\left[\begin{array}{ll}
\mathrm{J}_{\mathrm{P} \theta} & \mathrm{J}_{\mathrm{PV}} \\
\mathrm{J}_{\mathrm{Q}} & \mathrm{J}_{\mathrm{QV}}
\end{array}\right]\left[\begin{array}{l}
\Delta \theta \\
\Delta \mathrm{V}
\end{array}\right]
$$

where,

$\Delta \mathrm{P}$ is the incremental change in bus real power.

$\Delta Q$ is the incremental change in bus reactive power injection.

$\Delta \theta$ is the incremental change in bus voltage angle.

$\Delta \mathrm{V}$ is the incremental change in bus voltage magnitude.

$J_{P Q}, J_{P V}, J_{Q Q}, J_{Q V}$ are the power flow Jacobian elements.

System voltage stability is affected by both real and reactive power. However, at each operating point the real power is kept constant and voltage stability is evaluated by considering the incremental relationship between reactive power and voltage. This is analogous to the Q-V curve approach. Although incremental changes in real power are neglected in the formulation, the effects of changes in system load or power transfer levels are taken into account by studying the incremental relationship between reactive power and voltage at different operating conditions.

To reduce ( 3.6 ), let $\Delta P=0$, then

$$
\begin{aligned}
\Delta Q & =\left[J_{Q v}-J_{Q \theta} J_{P \theta}{ }^{-t} J_{P V}\right] \Delta V \\
& =J_{R} \Delta V
\end{aligned}
$$

and,

$$
\Delta \mathrm{V}=\mathrm{J}_{\mathrm{R}}{ }^{-1} \Delta \mathrm{Q}
$$

where,

$$
J_{R}=\left[J_{Q V}-J_{Q \theta} J_{P Q}{ }^{-1} J_{P V}\right]
$$


$J_{R}$ is called the reduced Jacobian matrix of the system. $J_{R}$ is the matrix which directly relates the bus voltage magnitude and bus reactive power injection. Eliminating the real power and angle part from the system steady state equations allows one to focus on the study of the reactive demand and supply problem.

Voltage stability characteristics of the system can be identified by computing the eigenvalues and eigenvectors of the reduced Jacobian matrix $\mathrm{J}_{\mathrm{R}}$. Let,

$$
\begin{aligned}
& J_{R}=\xi \wedge \eta \\
& \text { where, } \\
& \xi=\text { right eigenvector matrix of } J_{R} . \\
& \eta=\text { left eigenvector matrix of } J_{R} . \\
& \Lambda=\text { diagonal eigenvalue matrix of } J_{R} .
\end{aligned}
$$

and

$$
J_{R}^{-1}=\xi \Lambda^{-1} \eta
$$

From ( 3.7 ) and ( 3.9 ), we have,

$$
\text { or } \begin{aligned}
\Delta \mathrm{V} & =\xi \Lambda^{-1} \eta \Delta \mathrm{Q} \\
\Delta \mathrm{V} & =\sum_{i} \frac{\xi_{i} \eta_{i}}{\lambda_{i}} \Delta \mathrm{Q}
\end{aligned}
$$

Each eigenvalue $\lambda$, and the corresponding right and left eigenvectors $\xi_{i}$ and $\eta_{i}$ define the $i^{\text {it }}$ mode of the $\mathrm{Q}-\mathrm{V}$ response.

Since $\xi^{-1}=\eta$, equation 3.10 can be written as

$$
\begin{array}{cc} 
& \eta \Delta V=\Lambda^{-1} \eta \Delta Q \\
\text { or } & v=\Lambda^{-1} \mathrm{q} \\
\text { where, } \quad \mathrm{v}= & \eta \Delta \mathrm{V} \text { is the vector of modal voltage variaticns. } \\
\mathrm{q} & =\eta \Delta \mathrm{Q} \text { is the vector of modal reactive power variation. }
\end{array}
$$


Thus for the $i^{\text {th }}$ mode,

$$
v_{i}=\frac{1}{\lambda_{i}} q_{i}
$$

If $\lambda_{i}>0$, the $i^{\text {th }}$ modal voltage and the $i^{\text {th }}$ modal reactive power variation are along the same direction, indicating that the system is voltage stable. If $\lambda_{i}<0$, the $i^{\text {th }}$ modal voltage and the $i^{\text {th }}$ modal reactive power variation are along opposite direction, indicating that the system is unstable. In this sense, the magnitude of $\lambda_{i}$ determines the degree of stability of the $\mathrm{i}^{\text {th }}$ modal voltage. The smaller the magnitude of positive $\lambda_{i}$, the closer the $i^{\text {th }}$ modal voltage is to being unstable. When $\lambda_{i}=0$, the $i^{\text {th }}$ modal voltage collapses because any change in that modal reactive power causes infinite change in the modal voltage.

The magnitude of the eigenvalues can provide a relative measure of the proximity to instability. Eigenvalues do not, however, provide an absolute measure because of the non-linearity of the problem. The application of modal analysis heips in identifying the voltage stability critical areas and elements which participate in each mode.

The bus participation factors determine the contribution of $\lambda$, to the $\mathrm{V}-\mathrm{Q}$ sensitivity at bus $\mathbf{k}$. They can be expressed in terms of the left and right eigenvectors of $J_{R}$ as

$$
P_{k i}=\xi_{b i} \eta_{i k}
$$

Bus participation factors determine the areas associated with each mode. The size of bus participation in a given mode indicates the effectiveness of remedial actions applied at that bus in stabilizing the mode. 
The branch participation factors $\mathrm{P}_{\mathrm{ji}}$ which give the relative participation of branch $j$ in mode $i$ are given by

$$
P_{j i}=\frac{\Delta Q \text { loss for branch } j}{\max . \Delta Q \text { loss for all branches }}
$$

The $\Delta Q$ loss can be calculated by calculating the $\Delta V$ and $\Delta \theta$ change at both ends of the branch. Branch participation factors indicate for each mode, which branches consume the most reactive power in response to an incremental change in reactive load. Branches with high participations are either weak links or are heavily loaded. Branch participations are useful for identifying remedial measures to alleviate voltage stability problems and for contingency selection.

The generator participation factors $\mathrm{P}_{\mathrm{mi}}$ which give the relative participation of machine $\mathrm{m}$ in mode $\mathrm{i}$ are given by

$$
P_{m i}=\frac{\Delta Q \text { for machine } m}{\max . \Delta Q \text { for all machines }}
$$

The generator participation factors can be used to determine the generators that supply the most reactive power on demand. Generator participation provide important information regarding proper distribution of reactive reserves among all the machines in order to maintain an adequate voltage stability margin.

\subsection{Simulation Results and Discussions}

In this section, two typical test systems: the New England 39 bus system [9] and the IEEE 30 bus system [20], are simulated to illustrate the modal 
analysis along with continuation power flow technique used for the voltage stability evaluation.

\subsubsection{IEEE 30 bus system}

The single line diagram of the IEEE 30 bus system is shown in Fig.3.2. In this system, the load is increased at buses 3,12,21,26 and 30, while generation at buses $2,5,8,11$ and 13 are scaled accordingly to meet the increased demand. In this system, the base case system load corresponding to the selected buses is $45.2 \mathrm{MW}$.

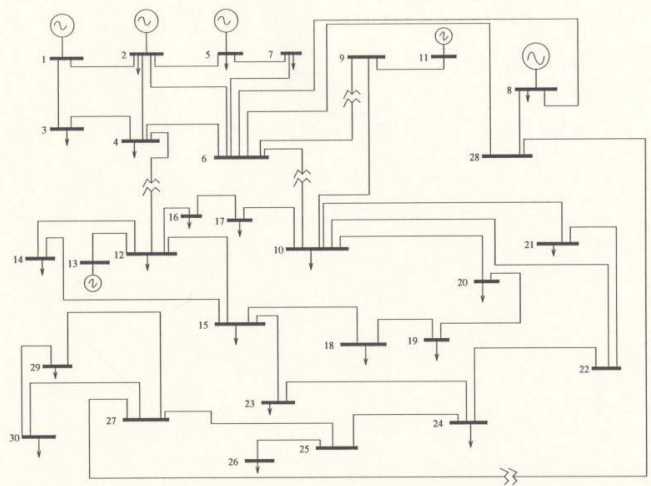

Fig.3.2 Single line diagram of the IEEE 30 bus system 
If the load in this system is uniformly increased ( constant power factor), and the power scaled up accordingly, the PV curve shown in Fig.3.3 is obtained from which it is seen that the voltage stability limit is $\mathbf{1 7 9 . 3 8}$ MW.

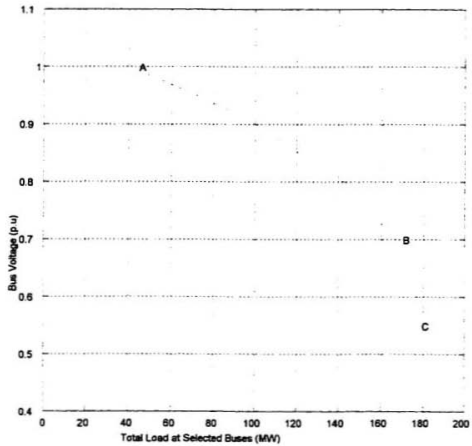

Fig.3.3 PV curve for bus 30 of the IEEE 30 bus system

Here, the PV curve is obtained up to the nose point using the continuation power flow technique. On this PV curve, three operating points are identified:

Point A: base case condition

$\mathrm{LOAD}=45.2 \mathrm{MW}$. 
Point B: near the voltage stability limit $L O A D=170.2 \mathrm{MW}$.

Point $\mathrm{C}$ : at the voltage stability limit $L O A D=179.3 \mathrm{MW}$.

Now modal analysis is performed at the three operating points to find five least stable modes for each case. Table 3.1 shows the results of the analysis for the three operating cases.

Table 3.1 Five smallest eigenvalues for the three operating cases

\begin{tabular}{|c|c|c|c|c|c|c|}
\hline & & \multicolumn{5}{|c|}{ Eigenvalues } \\
\hline $\begin{array}{l}\text { Operating } \\
\text { Point }\end{array}$ & $\begin{array}{l}\text { Total Load } \\
\text { (MW) }\end{array}$ & $\begin{array}{c}\text { mode } \\
\# 1\end{array}$ & $\begin{array}{l}\text { mode } \\
\# 2\end{array}$ & $\begin{array}{c}\text { mode } \\
\# 3\end{array}$ & $\begin{array}{c}\text { mode } \\
\# 4\end{array}$ & $\begin{array}{c}\text { mode } \\
\# 5\end{array}$ \\
\hline A & 45.2 & 0.5145 & 1.0644 & 1.7985 & 3.7182 & 4.2255 \\
\hline B & 170.2 & 0.1538 & 0.7068 & 0.9707 & 2.9505 & 3.2571 \\
\hline C & 179.3 & 0.0107 & 0.5697 & 0.8492 & 2.3959 & 2.8459 \\
\hline
\end{tabular}

From Table 3.1., it is seen that the minimum eigenvalue for operating points A, B, C are $0.5145,0.1538$ and 0.0107 respectively. Table 3.2 shows bus, branch and generator participation factors for the base case ( point A ) and at the voltage stability limit ( point C) corresponding to the least stable mode ( mode \#1).

Table 3.2 Participation factors ( P.F ) for base case and critical case corresponding to the least stable mode.

\begin{tabular}{|l|c|c|c|c|c|c|}
\hline Operating & \multicolumn{2}{|c|}{ Bus Participation } & \multicolumn{2}{|c|}{ Branch Participation } & \multicolumn{2}{|c|}{ Generator Participation } \\
Point & Bus No & P.F & \multicolumn{2}{|c|}{ Branch No } & P.F & \multicolumn{2}{|c|}{ Generator No } & P.F \\
\hline Point A & 30 & 0.2145 & $4-12$ & 1.0000 & 8 & 1.0000 \\
& 29 & 0.1940 & $9-11$ & 0.6622 & 13 & 0.5733 \\
& 26 & 0.1740 & $28-27$ & 0.5691 & & \\
\hline Point C & 30 & 0.4789 & $27-30$ & 1.0000 & 8 & 1.0000 \\
& 29 & 0.2463 & $28-27$ & 0.9834 & & \\
\hline
\end{tabular}


The above analysis shows that as the system load increases, the magnitude of the eigenvalue decreases and at the point of instability, it becomes essentially zero. Table 3.2 indicates that, at the point of instability, buses 30,29 and branches $27-30,28-27$ are prone to voltage instability. This can be justified from the fact that, for the least stable mode, buses 30 and 29 participate significantly while the rest of the buses do not contribute to voltage instability. This is evident from their participation factors. Table 3.3 gives the voltage stability margin for the three operating cases.

Table 3.3 Voltage stability margin for different operating conditions

\begin{tabular}{|c|c|c|}
\hline Operating Point & Total Load (MW) & Voltage Stability Margin (MW) \\
\hline A & 45.2 & 134.1 \\
\hline B & 170.2 & 9.1 \\
\hline C & 179.3 & 0 \\
\hline
\end{tabular}

Voltage stability margin ( VSM ) is a measure of how close the system is to voltage instability. It is defined as the difference between the values of a Key System Parameter (KSP) at the current operating condition and the voltage stability critical point [17]. Here, KSP is defined as the total load increase in the selected buses. For example, the voltage stability margin for the base case operating condition is $134.1 \mathrm{MW}$ and near the stability limit ( operating point B ) is $9.1 \mathrm{MW}$.

\subsubsection{New England 39 bus system}

In this section, modal analysis for the New England 39 bus system [9] is performed. This system is widely used for voltage stability evaluation. The single line diagram of the New England 39 bus system is shown in 
Fig.3.4. Here, the load is increased at buses $3,4,12,15$ and 21 . Generation at $30,32,35$ and 37 are scaled accordingly to meet the increased demand.

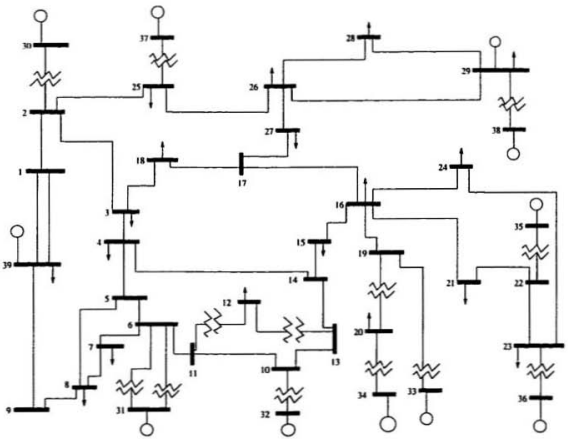

Fig.3.4 Single line diagram of New England 39 bus system

The PV curve for bus 12 of the New England 39 bus system is shown in Fig.3.5. Table 3.4 shows five least stable modes for the three operating cases. Operating point A corresponds to $1424.5 \mathrm{MW}$, operating point $\mathrm{B}$ 
corresponds to $4949.5 \mathrm{MW}$ and operating point C corresponds to 4976.8 MW.

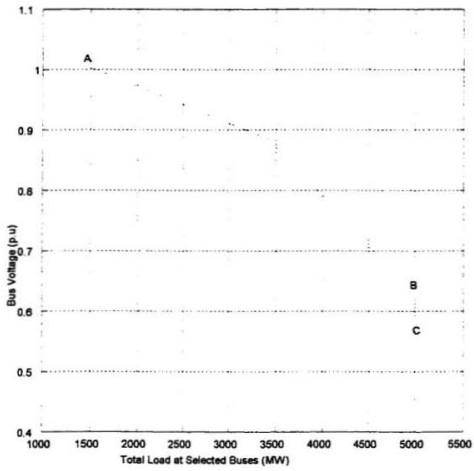

Fig.3.5 PV curve for bus 12 of the New England 39 bus system

Table 3.4 Five smallest eigenvalues for different loading conditions

\begin{tabular}{|l|c|c|c|c|c|c|}
\hline $\begin{array}{l}\text { Operating } \\
\text { Point }\end{array}$ & Total Load & \multicolumn{5}{|c|}{ Eigenvalues } \\
(MW) & mode 1 & mode 2 & mode 3 & mode 4 & mode 5 \\
\hline Point A & 1424.5 & 10.1145 & 22.5085 & 39.8117 & 45.4208 & 61.3524 \\
\hline Point B & 4949.5 & 0.9424 & 10.5001 & 16.3547 & 28.2210 & 35.0747 \\
\hline Point C & 4976.8 & 0.0661 & 9.4517 & 14.3959 & 26.9159 & 32.0200 \\
\hline
\end{tabular}


Table 3.5 gives bus, branch and generator participation factors for critical case (at the point of instability ) corresponding to the least stable mode.

Table 3.5 Participation factors ( P.F ) for critical case ( point C) corresponding to the least stable mode (mode 1 )

\begin{tabular}{|c|c|c|c|c|c|}
\hline \multicolumn{2}{|c|}{$\begin{array}{c}\text { Bus Participation } \\
\text { Bus No }\end{array}$} & \multicolumn{2}{|c|}{ Branch Participation } & \multicolumn{2}{|c|}{ Generator Participation } \\
\hline 12 & 0.1713 & $10-32$ & 1.0000 & 32 & 1.0000 \\
4 & 0.1042 & & & 31 & 0.7317 \\
14 & 0.0949 & & & & \\
\hline
\end{tabular}

From the above results, it can be concluded that the weakest buses and branch associated with this system are 12, 4, 14 and 10-32 respectively. Table 3.6 shows the voltage stability margin for the three operating cases considered.

Table 3.6 Voltage stability margin for the three operating conditions

\begin{tabular}{|c|c|c|}
\hline Operating Point & Total Load ( MW) & Voltage Stability Margin ( MW ) \\
\hline Point A & 1424.5 & 3552.3 \\
\hline Point B & 4949.5 & 27.3 \\
\hline Point C & 4976.8 & 0 \\
\hline
\end{tabular}

\subsection{Summary}

This chapter has presented a voltage stability assessment technique for large power systems using modal analysis in conjunction with continuation power flow technique. The method computes a specified number of the smallest eigenvalues of a reduced Jacobian matrix and the associated bus, branch and generator participations. Two typical test systems namely IEEE 30 bus system and New England 39 bus system were used for the purpose of analysis. 
The above two examples clearly indicate how the modes represent areas prone to voltage instability. Based on the simulation results, the following conclusions can be reached:

- Each eigenvalue corresponds to a mode of voltage/reactive power variation.

- The modes corresponding to small eigenvalue represent the modes most prone to loss of stability.

- The magnitude of each small eigenvalue provides a relative measure of proximity to loss of voltage stability for that mode.

Bus, branch and generator participations provide useful information regarding the mechanism of loss of stability.

- Bus participations indicate which buses are associated with each mode.

- Branch participations show which branches are important in the stability of a given mode.

- Generator participations indicate which machines must retain reactive reserves to ensure the stability of a given mode.

- The modal analysis along with continuation power flow can be used to determine the voltage stability margin for the base case and a large number of operating cases.

- Participation factors for the critical case corresponding to the least stable mode is most useful for any remedial actions. It clearly identifies groups of buses and critical bus that participate in the instability and thereby eliminate the problems associated with traditional methods. Identifying the critical bus will help in taking appropriate control actions. Hence, in the subsequent chapters, this method is used as basis for developing an expert system for voltage stability evaluation. 


\section{Chapter 4}

\section{FUZZY-EXPERT SYSTEMS}

\subsection{Introduction}

As mentioned in chapter two, expert systems are built based on the knowledge acquired from domain experts. The knowledge of an expert system may be represented in a number of ways. One common method of representing knowledge is in the form of IF-THEN type rules, such as

IF the light is red THEN stop

If a fact exists that the light is red, this matches the pattern "the light is red". The rule is satisfied and performs its action of "stop".

Expert systems can be considered declarative programming because the programmer does not specify how a program is to achieve its goal at the level of an algorithm. Expert systems are generally designed very differently from conventional programs because the problems usually have no algorithmic solution and rely on inferences to achieve a reasonable solution.

The strength of an expert system can be exploited fully when it is used in conjunction with a database. Changes in the system operating conditions are reflected in the database. The expert system that draws its data from the database automatically tracks the system operating conditions.

The purpose of this chapter is to introduce the basic theory of expert systems and fuzzy logic. The concept of membership function plays an important role in the design of the proposed fuzzy-expert system for 
voltage stability monitoring and control. Hence, it is relevant to explore these concepts in detail to understand its applicability to power system problems. One of the objective of this thesis is to arrive at a solution that is fast, reliable and useful for the power system operators. This chapter will lay a foundation in understanding the proposed fuzzy-expert system in order to achieve the desired objective.

In this chapter, the theory of expert system is described in section 4.2 . The fundamental concepts of furzy set theory is explained in section 4.3. Section 4.4 highlights potential applications of fuzzy-set-based approaches and their relevance to power system problems.

\subsection{Expert System Structure}

The structure of an expert system in a general block diagram is shown in Fig. 4.1 [21].

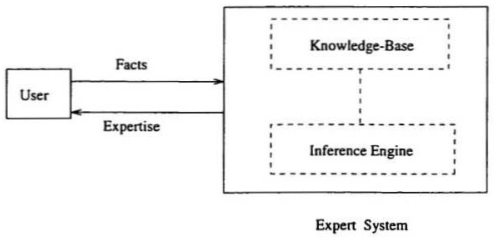

Fig.4.1 Expert system structure 
The above two examples clearly indicate how the modes represent areas prone to voltage instability. Based on the simulation results, the following conclusions can be reached:

- Each eigenvalue corresponds to a mode of voltage/reactive power variation.

- The modes corresponding to small eigenvalue represent the modes most prone to loss of stability.

- The magnitude of each small eigenvalue provides a relative measure of proximity to loss of voltage stability for that mode.

Bus, branch and generator participations provide useful information regarding the mechanism of loss of stability.

- Bus participations indicate which buses are associated with each mode.

- Branch participations show which branches are important in the stability of a given mode.

- Generator participations indicate which machines must retain reactive reserves to ensure the stability of a given mode.

- The modal analysis along with continuation power flow can be used to determine the voltage stability margin for the base case and a large number of operating cases.

- Participation factors for the critical case corresponding to the least stable mode is most useful for any remedial actions. It clearly identifies groups of buses and critical bus that participate in the instability and thereby eliminate the problems associated with traditional methods. Identifying the critical bus will help in taking appropriate control actions. Hence, in the subsequent chapters, this method is used as basis for developing an expert system for voltage stability evaluation. 
As shown in Fig.4.1., the expert system consists of two components. The knowledge-base and the inference engine. The knowledge-base comprises knowledge that is specific to the domain of application, including simple facts about the domain, rules that describe relations or phenomena in the domain and heuristics.

The inference engine actively uses the knowledge in the knowledge-base and draws conclusions. The user interface provides smooth communication between the user and the system. It also provides the user with an insight into the problem-solving process executed by the inference engine. It is convenient to view the inference engine and the interface as one module, usually called an expert system shell.

Expert systems are often designed to deal with uncertainty because reasoning is one of the best tools that have been discovered for dealing with uncertainty. The uncertainty may arise in the input data to the expert system and even the knowledge-base itself. At first this may seem surprising to people used to conventional programming. However, much of human knowledge is heuristic, which means that it may only work correctly part of the time. In addition, the input data may be incorrect, incomplete, inconsistent and have other errors. Algorithmic solutions are not capable of dealing with situations like this.

Depending on the input data and the knowledge-base, an expert system may come up with the correct answer, a good answer, a bad answer or no answer at all. While this may seem shocking at first, the alternative is no answer all the time. 


\subsection{Theory of Approximate Reasoning [21]}

\subsubsection{Fuzzy set theory}

The theory of uncertainty is based on fuzzy logic. The traditional way of representing which objects are members of a set is in terms of a characteristic function, sometimes called a discrimination function. If an object is an element of a set, then its characteristic function is 1 . If an object is not an element of a set, then its characteristic function is 0 . This definition is summarized by the following characteristic function:

$$
\begin{aligned}
& \mu_{\mathrm{A}}(\mathrm{x})=1 \text { if } \mathrm{x} \text { is an element of set } \mathrm{A} \\
& 0 \text { if } x \text { is not an element of set } A
\end{aligned}
$$

where the objects $x$ are elements of some universe $\mathrm{X}$.

$$
\mu_{\mathrm{A}}(\mathrm{x}): \mathrm{X} \rightarrow\{0,1\}
$$

In fuzzy sets, an object may belong partially to a set. The degree of membership in a fuzzy set is measured by a generalization of the characteristic function called the membership function or compatibility function defined as

$$
\mu_{\mathrm{A}}(\mathrm{x}): \mathrm{X} \rightarrow[0,1]
$$

The characteristic function maps all elements of $\mathrm{X}$ into one of exactly two elements: $\mathbf{0}$ or $\mathbf{1}$. In contrast, the membership function maps $\mathrm{X}$ into the codomain of real numbers defined in the interval from 0 to 1 inclusive. That is, the membership function is a real number 


$$
0 \leq \mu_{\mathrm{A}} \leq 1
$$

where 0 means no membership and 1 means full membership in the set. A particular value of the membership function, such as 0.5 , is called a grade of membership.

For example, if a person is an adult, then anyone about 7 feet and taller is considered to have a membership function of 1.0. Anyone less than 5 feet is not considered to be in the fuzzy set TALL and so the membership function is 0 . Between 5 and 7 feet, the membership function is monotonically increasing with height. This particular membership function is only one of many possible functions. The membership function for the Fuzzy set TALL is shown in Fig.4.2

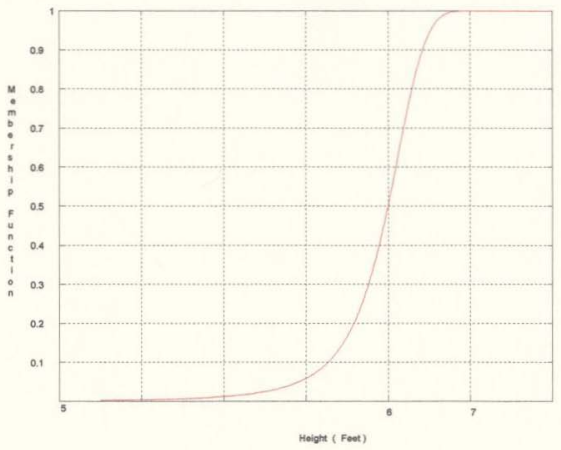

Fig.4.2 Membership function for the fuzzy set TALL 
The S-function and $\Pi$ function are two important mathematical functions that are often used in fuzzy sets as membership functions. They are defined as follows:

$$
s(x ; \alpha, \beta, \gamma)= \begin{cases}0 & \text { for } \mathrm{x} \leq \alpha \\ 2\left(\frac{\mathrm{x}-\alpha}{\gamma-\alpha}\right)^{2} & \text { for } \alpha \leq \mathrm{x} \leq \beta \\ 1-2\left(\frac{\mathrm{x}-\gamma}{\gamma-\alpha}\right)^{2} & \text { for } \beta \leq \mathrm{x} \leq \gamma \\ 1 & \text { for } \mathrm{x} \geq \gamma\end{cases}
$$

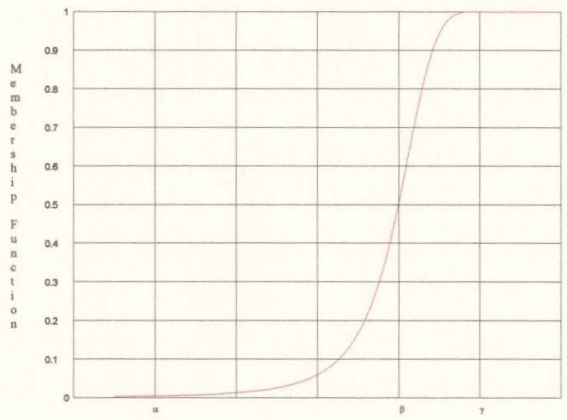

Fig.4.3 The S-function 


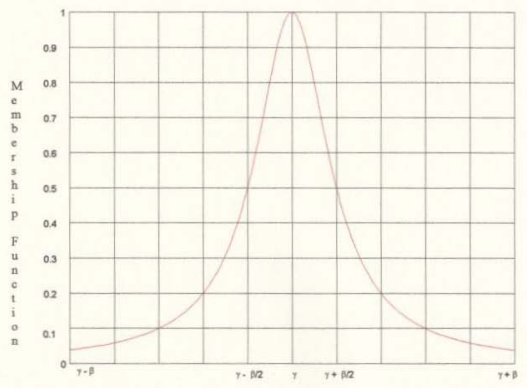

Fig.4.4 The $\Pi$ - function

The $\Pi$-function is shown in Figure 4.4. Notice that the $\beta$ parameter is now the bandwidth or total width at the crossover points. The $\Pi$-function goes to zero at the points $\mathrm{x}=\gamma \pm \beta$ while the crossover points are at $\mathrm{x}=\gamma \pm \frac{\beta}{2}$.

Fuzzy logic forms the basis of fuzzy-expert systems. In fuzzy-expert system, the knowledge is captured in natural language which have ambiguous meanings, such as tall, hot, dangerous and so on, which is concerned with the theory of uncertainty based on fuzzy logic. The theory is primarily concerned with quantifying the linguistic variable into possible fuzzy subsets. A linguistic variable is assigned values which are expressions such as words, phrases or sentences in a natural or artificial 
language. For example, the linguistic variable "height" has typical values like "dwarf", "short", "average", "tall", "giant". These values are referred to as fuzzy subsets. Every element in these fuzzy subsets has its own degree of membership. Besides dealing with uncertainty, fuzzy-expert systems are also capable of modeling commonsense reasoning, which is very difficult for conventional systems.

Fuzzy logic is the logic of approximate reasoning. Essentially, approximate or fuzzy reasoning is the inference of a possibly imprecise conclusion from a set of possibly imprecise premises. One of the important type of fuzzy logic is based on Zadeh's theory of approximate reasoning [22], which uses a fuzzy logic whose base is Lukasiewicz $L_{1}$ logic. In this fuzzy logic, truth values are linguistic variables that are ultimately represented by fuzzy sets.

Fuzzy logic operators based on the Lukasiewicz operators are defined in the Table 4.1. $x(A)$ is a numeric truth value in the range $[0,1]$ representing the truth of the proposition " $\mathrm{x}$ is $\mathrm{A}$ ", which can be interpreted as the membership grade $\mu_{\mathrm{A}}(\mathrm{x})$.

Table 4.1 Fuzzy logic operators

$x\left(A^{\prime}\right)=x($ NOT $A)=1-\mu_{A}(x)$
$x(A) \wedge x(B)=x($ A AND B $)=\min \left(\mu_{A}(x), \mu_{B}(x)\right)$
$x(A) \vee x(B)=x($ A OR B $)=\max \left(\mu_{A}(x), \mu_{B}(x)\right)$
$x(A) \rightarrow x(B)=x(A \rightarrow B)=\max \left[\left(1-\mu_{A}(x)\right), \mu_{B}(x)\right]$




\subsection{Application of Fuzzy-Set Theory to Power Systems}

One of the fundamental objectives in the management of power systems is to provide safe and reliable electric power at the lowest possible cost. To achieve this objective, rapid advances in the control and management technology of power systems has been made. For example, ABB's Energy Management Systems ( EMSYS ) [23] is an innovative, computer-based information and control system designed to provide full range of utility solutions, from basic SCADA to advanced transmission system network security and distribution automation applications.

During this process, power systems have become even more complex in structure and status. This growing complexity is causing problems to power system operators. Some of the more evident problems are:

- $\quad$ rapid increase in the number of real-time messages has made operator response more difficult.

- current numerical processing software cannot meet the operational requirements of power systems in some situations. Typical example is processing difficulty during emergency conditions.

- most design, planning and control problems encountered are complex and time consuming because of multiple objective functions, multiple constraints, and complex system interactions.

Analytical solution methods exist for many power systems operation, planning and control problems. However, the mathematical formulations of real-world problems are derived under certain restrictive assumptions and even with these assumptions, the solutions of large scale power systems problems is not trivial. On the other hand, there are many 
uncertainties in various power systems problems because power systems are large, complex and influenced by unexpected events. These facts make it difficult to effectively deal with many power systems problems through strict mathematical formulations alone. Therefore, expert systems approaches have emerged in recent years as a complement to mathematical approaches and have proved to be effective when properly coupled together.

Reference [24] gives a bibliographical survey of the research, development and applications of expert systems in electric power systems. As already mentioned, expert systems are built based on the knowledge acquired from domain experts. The expert's empirical knowledge is generally expressed by language containing ambiguous or fuzzy descriptions. As a result, a number of researchers have applied fuzzy logic concept to power system applications. Some of the applications include fuzzy approach to power system security [25], dynamic generation rescheduling [26], reactive power/voltage control [27], short-term load forecasting [28], prioritizing emergency control [29], contingency constrained optimal power flow [30]. A more comprehensive list of applications of fuzzy set theory to power systems is given in [31].

When fuzzy set theory is used to solve real problems, the following steps are generally followed [31]:

step 1 Description of the original problem. The problem to be solved should first be stated mathematically/inguistically.

step 2 Definition of thresholds for variables.

step 3 Fuzzy quantization. Based on the threshold values from step 2, proper forms of membership functions are constructed. Many forms of 
- In approximate reasoning, the attributes included in the rules are given by linguistic variables. A linguistic variable measures the proximity of a given value to a fuzzy set by the grade of membership to the set. Such grading of attributes are known as uncertainty factors.

- Approximate reasoning permits multi-attribute evaluation of an input because every condition included in a rule has a numerical value, rather than true or false state as in conventional expert system.

In the overall context of the research, this chapter introduces the theory behind the proposed fuzzy-expert system for voltage stability monitoring and control. 


\section{Chapter 5}

\section{FUZZY CONTROL APPROACH TO VOLTAGE PROFILE ENHANCEMENT FOR POWER SYSTEMS}

\subsection{Introduction}

The application of fuzzy set theory to power systems is a relatively new area of research. Chapter 4 has highlighted the basic principles involved in this area. However, before attempting to develop a fuzzy concept for voltage stability evaluation, the fuzzy set theory is first applied to voltagereactive power control for power systems.

As the voltage profile of the electric power system could be constantly affected, either by the variations of load or by the changes of network configuration, a real-time control is required to alleviate the problems caused by the perturbations. The problem is how to accurately compose a voltage control strategy during emergency conditions when complete system information is not available. To overcome this problem, adjustments to the control devices are needed after the perturbations to alleviate voltage limit violations. This can be achieved by determining the sensitivity coefficients of the control devices.

Several papers in the literature explore voltage/reactive power control by means of fuzzy sets [33], heuristic and algorithmic [34], rule-based systems [35] etc. In this chapter, a voltage-reactive power control model using fuzzy sets is described which aims at the enhancement of voltage security. In this model, two linguistic variables are applied to measure the proximity of a given quantity to a certain condition to be satisfied. The 
two linguistic variables are the bus voltage violation level and the controlling ability of control devices. These are translated to fuzzy domain to formulate the relation between them. A feasible solution set is first attained using min- operation of fuzzy sets, then the optimal solution is determined employing the max- operation. The method was proposed by Ching-Tzong Su and Chien-Tung Lin [36].

\subsection{Problem Statement}

In power system operation, any changes to system topology and power demand can cause a voltage violation. When a voltage emergency has been identified, control actions must be initiated, either automatically or manually, to alleviate the abnormal condition. The reaction time is critical. For example, when a destructive storm passes through an area, communication systems can be disrupted, reducing the information received at the system control center. If bus voltages are beyond desirable limits during such an emergency, the voltage control problem cannot be solved by conventional methods i.e., using load flow solution techniques. This is due to incomplete information needed to construct the system network model.

Optimal control of voltage and reactive power is a significant technique for improvements in voltage profiles of power system. The objective is to improve the system voltage profile, such that it will lead as closely as possible to the desired system condition. The network constraints include the upper and lower bounds of bus voltage magnitudes as well as the adjustable minimum and maximum quantities of controlling devices. When a load bus voltage violates the operational limits, control actions must be taken to alleviate the abnormal condition. Consider an $\mathrm{N}$-bus 
system, with buses 1 to $\mathrm{L}$ as load buses, buses $\mathrm{L}+\mathrm{l}$ to $\mathrm{N}-1$ as generator buses. By adjusting the controlling device on bus $\mathrm{j}$, the voltage improvement of bus $i$ is given by

$$
\begin{gathered}
\Delta \mathrm{V}_{\mathrm{i}}=\mathrm{S}_{\mathrm{ij}} \Delta \mathrm{U}_{\mathrm{i}} \\
\mathrm{i}=1,2, \ldots ., \mathrm{L} ; \mathrm{j}=1,2, \ldots \ldots, \mathrm{N}-1
\end{gathered}
$$

where, $\Delta \mathrm{V}_{i}$ is the voltage change of bus $\mathrm{i}$.

$S_{i j} \quad$ is the sensitivity coefficient of bus $j$ on bus $i$.

$\Delta U_{j}$ is the adjustment of controlling device at bus $j$.

Sensitivity coefficient in general gives an indication of the change in one system quantity ( $\mathrm{eg}$ : bus voltage, MW flow etc. ) as another quantity is varied ( VAR injection, generator voltage magnitude, transformer tap position etc. ). Here, the assumption is that as the adjustable variable is changed, the power system reacts so as to keep all of the power flow equations solved. As such, sensitivity coefficients are linear and are expressed as partial derivatives. For example, expression 5.2 represents the sensitivity of voltage at bus $i$ for reactive power injected at bus $j$.

$$
\frac{\partial V_{i}}{\partial Q_{j}}
$$

Adjustment of the controlling device is constrained as

$$
\Delta U_{j}^{m i s} \leq \Delta U_{j} \leq \Delta U_{j}^{m * x}
$$

where, $\Delta U_{j}^{m i n}$ and $\Delta U_{j}^{m a x}$ represent the adjustable minimum and maximum reactive power.

The load bus voltage deviation should be controlled within $\pm 5 \%$ of the nominal voltage $\mathrm{V}^{\mathrm{a} \times \mathrm{m}}$, which can be expressed as

$$
V_{i}^{\min } \leq V_{i} \leq V_{i}^{\max }
$$


where, $V_{i}^{\text {mis }}\left(=0.95 \mathrm{~V}^{\mathrm{mos}}\right)$ and $\mathrm{V}_{\mathrm{i}}^{\mathrm{max}}\left(=1.05 \mathrm{~V}^{\mathrm{mom}}\right)$ are the lower and upper voltage limits of bus $i$ respectively and $V_{i}$ is the input of the system.

\subsection{Fuzzy Modeling}

Two linguistic variables namely, the bus voltage violation level and the controlling ability of controlling devices are modeled in the furzy domain as follows

\subsubsection{Bus voltage violation level}

The membership function of the bus voltage violations is shown in Fig.5.1. The maximum deviation of the bus voltage is $\Delta V_{i}^{m a x}=V_{i}^{m a x}-V^{n \circ m}$, the minimum deviation of bus voltage is $\Delta \mathrm{V}_{i}^{\text {min }}=V_{i}^{\text {mis }}-V^{\text {mom }}$. $\mathrm{V}_{i}^{\mathrm{mex}}, \mathrm{V}_{\mathrm{i}}^{\mathrm{min}}$ and $\mathrm{V}^{\mathrm{am}}$ take the values $1.05,0.95$ and 1.0 p.u. Here, it is desirable to control the bus voltage deviation within $\pm 5 \%$ of the nominal voltage.

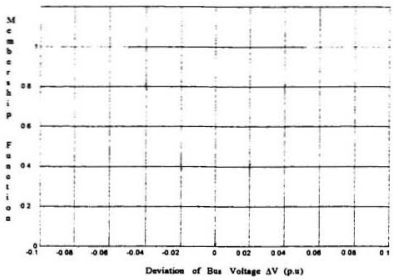

Fig.5.1 Furzy model for bus voltage violation level 


\subsubsection{Controlling ability of controlling devices}

The fuzzy representation of the controlling ability of the controlling device is shown in Fig.5.2. The controlling ability is

$$
C_{i j}=S_{i j} M_{j}
$$

where, $\mathbf{M}_{j}$ is the controlling margin of the controlling device at bus $\mathrm{j}$.

$S_{i j}$ is the sensitivity coefficient of bus $j$ on bus $i$.

$\mathrm{C}_{\mathrm{ij}}$ is the controlling ability for controlling device of bus $j$ on bus $\mathrm{i}$.

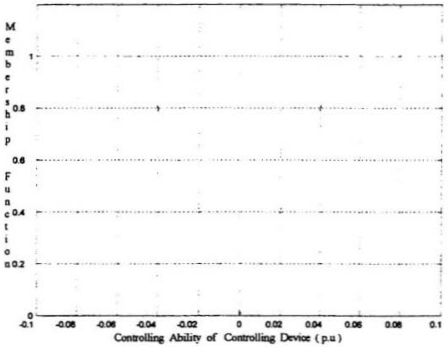

Fig.5.2 Fuzzy model of controlling ability of controlling device

\subsubsection{Control Strategy}

The violation of bus voltages and the controlling ability of the controlling devices are first fuzzified with the fuzzy models defined in Fig.5.1 and 
Fig.5.2. To alleviate the bus voltage violation, a suitable control strategy is adopted. The strategy consists of selecting an optimal controlling device and the adjustment of that device. The two most effective control devices are Static Var Compensators ( SVC ) and generator controls. Since, voltage violation is a local phenomena, SVC's are given a greater priority compared to generator controls [37].

The control strategy consists of three steps as described below:

- Let $\mu_{s v}$ and $\mu_{\mathrm{c}}$ be the membership value of voltage violation and controlling ability of the controlling device respectively for a particular controlled bus $i$. Select a controlling device $j$ with corresponding membership value $\mu_{\mathrm{e}}$ of controlling ability, take the min- operation

$$
\mathbf{R}_{i j}=\min \left(\mu_{\Delta v}, \mu_{e}\right)
$$

Repeat the above min-operation for all controlling devices.

- Take the max-operation to the $j$ terms of $R_{i j}$ obtained above.

$$
\mathrm{K}_{\mathrm{ij}}=\max \left(\mathbf{R}_{\mathrm{it}}, \mathbf{R}_{\mathrm{i}}, \ldots, \mathbf{R}_{\mathrm{q}}\right)
$$

where, $\mathrm{j}$ represents the total number of controlling devices.

- For each of the $\mathrm{L}$ controlled buses, repeat the min-max operations. $\mathrm{L}$ terms of $\mathrm{K}_{\mathrm{ij}}$ are obtained. Take the max- operation to the $L$ terms of $K_{i j}$.

$$
P_{i j}=\max \left(K_{1 j}, K_{2 j}, \ldots, K_{L i}\right)
$$

where, $P_{i j}$ represents the membership value of controlling ability for controlling device at controlling bus $\mathrm{j}$ on controlled bus $\mathrm{i}$.

Note that the above three operations are to be done independently for SVC and generator controllers. 


\subsection{Methodology}

The following are the computational steps involved in the fuzzy control approach for the voltage profile enhancement.

(1) For the given system and loading conditions, perform the base case load flow using a commercially available software package, for example, the Interactive Power Flow ( IPFLOW ) version 4.1.

(2) Identify those affected load bus voltages that violate either the upper or lower bound voltage limits.

(3) For the available controllers, find their sensitivity coefficients.

(4) Calculate the available control margin which is the difference between the present setting and the maximum possible setting of a particular controller.

(5) Find the membership value of bus voltage violation level and controlling ability.

(6) Evaluate the optimal control solution as described under control strategy in section 5.3 .

(7) Modify the value of the control variables.

(8) Perform the load flow study and output the results.

\subsection{Simulation Results and Discussions}

To verify the above method, a modified IEEE 30 bus test system is taken as a numerical example. Modifications are made to the original IEEE 30 bus system at bus 13 and bus 11 . Their pre-modified initial terminal voltages are 1.071 and 1.082 p.u respectively. Base case voltage profiles of the modified IEEE 30 bus system are shown in Table 5.1. In this system, the reactive power sources are assumed to be at buses $10,19,24$, 29 and generator voltage regulators at buses $2,5,8$. The following three cases are investigated 


\section{case 1:}

Load is increased at bus 26 , causing bus 26 to violate the voltage constraint, but the violation is not serious.

case 2:

Load is increased at buses 7 and 15 causing voltage violation at buses 15 , 18 and 23.

\section{case 3:}

For load increase at bus 15 and outage of line 12-15, buses 15 and 23 violate the voltage constraint.

Table 5.1 Base case voltage profiles of the modified IEEE 30 bus system

\begin{tabular}{|c|c|}
\hline Bus No & Bus Voltage ( p.u ) \\
\hline 1 & 1.0613 \\
\hline 2 & 1.0450 \\
\hline 3 & 1.0187 \\
\hline 4 & 1.0092 \\
\hline 5 & 1.0100 \\
\hline 6 & 1.0079 \\
\hline 7 & 1.0009 \\
\hline 8 & 1.0100 \\
\hline 9 & 1.0353 \\
\hline 10 & 1.0313 \\
\hline 11 & 1.0500 \\
\hline 12 & 1.0428 \\
\hline 13 & 1.0500 \\
\hline 14 & 1.0280 \\
\hline 15 & 1.0236 \\
\hline & \\
\hline
\end{tabular}




\begin{tabular}{|l|l|}
\hline 16 & 1.0307 \\
\hline 17 & 1.0257 \\
\hline 18 & 1.0140 \\
\hline 19 & 1.0115 \\
\hline 20 & 1.0157 \\
\hline 21 & 1.0191 \\
\hline 22 & 1.0197 \\
\hline 23 & 1.0137 \\
\hline 24 & 1.0091 \\
\hline 25 & 1.0085 \\
\hline 26 & 0.9907 \\
\hline 27 & 1.0169 \\
\hline 28 & 1.0044 \\
\hline 29 & 0.9969 \\
\hline 30 & 0.9853 \\
\hline
\end{tabular}

Table 5.2 shows the lower and upper limits of the available controllers. The values of the controllers Q10, Q19, Q24, Q29, V2, V5, V8 before the control action is initiated are $0,0,0,0,1.045,1.01,1.01$ respectively.

Table 5.2 Lower and upper limits of the controllers

\begin{tabular}{|c|c|c|}
\hline Controller Type & Lower Limit ( p.u ) & Upper Limit (p.u ) \\
\hline Q 10 & -1.0 & 1.0 \\
\hline Q 19 & -1.0 & 1.0 \\
\hline Q 24 & -1.0 & 1.0 \\
\hline Q 29 & -1.0 & 1.0 \\
\hline V2 & 0.95 & 1.05 \\
\hline V5 & 0.95 & 1.05 \\
\hline V8 & 0.95 & 1.05 \\
\hline
\end{tabular}


Table 5.3 compares the load bus voltage profiles before and after the control actions for the three cases considered and Table 5.4 shows the optimal fuzzy control solution.

Table 5.3 Load bus voltage profiles before and after control actions

\begin{tabular}{|c|c|c|c|c|c|c|}
\hline \multirow{3}{*}{$\begin{array}{l}\text { Load } \\
\text { Bus No } \\
3\end{array}$} & \multicolumn{2}{|c|}{$\begin{array}{c}\text { Case I } \\
\text { Voltages (p.u) }\end{array}$} & \multicolumn{2}{|c|}{$\begin{array}{c}\text { Case 2 } \\
\text { Voltages ( p.u ) }\end{array}$} & \multicolumn{2}{|c|}{$\begin{array}{c}\text { Case } 3 \\
\text { Voltages ( p.u ) }\end{array}$} \\
\hline & Initial & Final & Initial & Final & Initial & inal \\
\hline & 1.0178 & 1.0181 & 0.9983 & 1.0000 & 1.0156 & 1.0167 \\
\hline 4 & 1.0081 & 1.0085 & 0.9867 & 0.9887 & 1.0056 & 1.0070 \\
\hline 6 & 1.0068 & 1.0072 & 0.9912 & 0.9931 & 1,0041 & 1.0054 \\
\hline 7 & 1.0003 & 1.0006 & 0.9691 & 0.9703 & 0.9987 & 0.9995 \\
\hline 9 & 1.0337 & 1.0344 & 1.0170 & 1.0236 & I. .0248 & 1.0307 \\
\hline 10 & 1.0285 & 1.0298 & 1.0046 & 1.0173 & 1.0124 & 1.0238 \\
\hline 12 & 1.0414 & 1.0421 & 1.0067 & 1.0133 & 1.0400 & 1.0443 \\
\hline 14 & 1.0260 & 1.0269 & 0.9711 & 0.9806 & 0.9907 & 1.0026 \\
\hline 15 & 1.0208 & 1.0219 & 0.9391 & 0.9513 & 0.9400 & 0.9588 \\
\hline 16 & 1.0286 & 1.0295 & 0.9987 & 1.0079 & 1.0206 & 1.0279 \\
\hline 17 & 1.0232 & 1.0243 & 0.9974 & 1.0091 & 1.0093 & 1.0195 \\
\hline 18 & 1.0112 & 1.0123 & 0.9489 & 0.9614 & 0.9525 & 0.9797 \\
\hline 19 & 1.0087 & 1.0099 & 0.9581 & 0.9708 & 0.9632 & 0.9954 \\
\hline 20 & 1.0128 & 1.0140 & 0.9689 & 0.9816 & 0.9747 & 1.0017 \\
\hline 21 & 1.0153 & 1.0168 & 0.9892 & 1.0057 & 0.9969 & 1.0085 \\
\hline 22 & 1.0156 & 1.0173 & 0.9890 & 1.0066 & 0.9965 & 1.0082 \\
\hline 23 & 1.0085 & 1.0105 & 0.9463 & 0.9674 & 09498 & 0.9659 \\
\hline 24 & 1.0006 & 1.0038 & 0.9654 & 0.9980 & 0.9720 & 0.9844 \\
\hline 25 & 0.9888 & 0.9959 & 0.9785 & 1.0009 & 0.9851 & 0.9937 \\
\hline 26 & $\underline{0.9429}$ & 0.9504 & 0.9601 & 0.9829 & 0.9668 & 0.9755 \\
\hline 27 & 1.0043 & 1.0136 & 0.9956 & 1.0114 & 1.0020 & 1.0081 \\
\hline 28 & 1.0020 & 1.0033 & 0.9896 & 0.9926 & 0.9997 & 1.0012 \\
\hline 29 & 0,9840 & 1.0024 & 0.9751 & 0.9914 & 0.9817 & 0.9879 \\
\hline 30 & 0.9723 & 0.9871 & 0.9633 & 0.9797 & 0.9700 & 0.9763 \\
\hline
\end{tabular}


Table 5.4 Optimal fuzzy control solution

\begin{tabular}{|c|c|c|}
\hline $\begin{array}{l}\text { Case } \\
\text { No }\end{array}$ & $\begin{array}{l}\text { Controllers } \\
\text { Selected }\end{array}$ & $\begin{array}{l}\text { Final Value of the } \\
\text { Controllers ( p.u ) }\end{array}$ \\
\hline 1 & Q 29 & 0.0295 \\
\cline { 2 - 3 } & V8 & 1.01 \\
\hline \multirow{2}{*}{2} & Q 24 & 0.1520 \\
\cline { 2 - 3 } & V8 & 1.01 \\
\hline \multirow{2}{*}{3} & Q 19 & 0.1106 \\
\cline { 2 - 3 } & V8 & 1.01 \\
\hline
\end{tabular}

The results for case 1 in Table 5.3 show that the load increase at bus 26 causing bus 26 to violate the voltage limits. The lower and upper voltage limits are 0.95 and 1.05 p.u respectively. The voltage violation at bus 26 is 0.0071 . From Fig. 5.1., the membership value corresponding to the voltage violation, which in this case is $\mathbf{0 . 1 4 2}$, is obtained. Then, for all the available controllers, from the sensitivity analysis and from controlling margin of the controlling devices, the controlling ability of the controlling devices $\left(\mathrm{C}_{\mathrm{ij}}\right)$ is determined. From Fig 5.2, the membership values for these controlling abilities are obtained. Finally, by applying min-max operations, controllers Q29 and V8 are obtained as indicated in Table 5.4. To obtain the final value of the controller Q29, sensitivity analysis is performed. The sensitivity coefficient of the controller Q29 with respect to bus 26 is 0.0024 . Hence, the final value of Q29 is 0.0295 p.u.

If there is a voltage violation at more than one bus as in case 2 , then the above procedure has to be repeated for each violated bus independently. This is referred to as layer- 1 operation. Then from the selected controllers 
of layer-1, max operation is performed to arrive at the proper solution. This is known as layer-2 operation.

\subsection{Summary}

In this chapter, a simple method using fuzzy sets for the voltage-reactive power control to improve the system voltage level is presented. The control strategy is obtained by employing max-min operations. A modified IEEE 30 bus system is used as an example to illustrate this method. From the simulation results, it can be inferred that fuzzy models are indeed effective in power system control applications. One of the desirable feature of this fuzzy model is that if the operator is not satisfied with the grading of the fuzzy model, the operator can adjust the parameters associated in the definition of the membership function to suite the needs of the desired system operation. 


\section{Chapter 6}

\section{FUZZY-EXPERT SYSTEM FOR VOLTAGE STABILITY MONITORING AND CONTROL}

\subsection{Introduction}

In the preceding chapters, considerable attention has been given to the concepts of voltage stability, modal analysis technique, fuzzy-expert systems and their application to typical test systems. Simulation results of these test systems are encouraging and have been a motivation to investigate this concept for the voltage stability problem. In this chapter, a new fuzzy-expert system is proposed for voltage stability monitoring and control.

The phenomena of voltage stability can be attributed to slow variation in system load or large disturbances such as loss of generators, transmission lines or transformers. The impact of these changes leads to progressive voltage degradation in a significant part of the power system causing instability.

In the context of real-time operation, voltage stability analysis should be performed on-line. A number of special algorithms and methods have been discussed in chapter 2 . However, these methods require significant computation time. When the power system is operating close to its limits, it is essential for the operator to have a clear knowledge of the operating state of the power system. For on-line applications, there is a need for tools that can quickly detect the potentially dangerous situations of voltage 
instability and provide guidance to steer the system away from voltage collapse.

In an effort to improve the speed and ability to handle stressed power systems, a fuzcy-expert system approach is proposed. A number of researchers have made an attempt in this direction. An expert system prototype was developed to correct for voltage steady state stability [38]. In this approach, an expert system arrives at a fast solution by considering an overall system threshold indicator to decide on the degree of VAR shortage and the vuinerability of the system to voltage instability. YuanYih Hsu and Chung-Ching Su [39] proposed a rule-based expert system for small-signal stability analysis. They developed an efficient on-line operational aid, wherein the expert system performs deductive reasoning to arrive at the degree of stability without the need to calculate the eigenvalues. In this chapter, a fuzzy-expert system approach to steadystate voltage stability monitoring and control is proposed. The results of chapter five have been a useful starting point for this new approach. The proposed expert system evaluates system state through deductive reasoning by operating on a set of fuzzy rulebase. The furzy rulebase is system dependent, but once formed, it can handle any operating condition. An integrated approach of expert systems and conventional power system solution methodologies has the potential to provide real-time monitoring and control.

The chapter is organized as follows. Section 6.2 highlights the concepts of fuzzy-expert system, design of database and rulebase specifically for the New England 39 bus system. Sections 6.3 and 6.4 present the inference 
engine and simulation results of the New England 39 bus system respectively. Section 6.5 provides a summary of this new approach.

\subsection{Expert System and Design}

Expert system consists of two main components. The knowledge-base and the inference engine. A knowledge-base is a collection of facts and rules describing how the facts are linked. Based on the facts, the expert system draws conclusions by the inference engine.

In fuzzy-expert system, the knowledge is captured in natural language which have ambiguous meanings, such as tall, hot and dangerous, and is concerned with the theory of uncertainty based on fuzzy logic. The theory is primarily concerned with quantifying the linguistic variable say "tall" into possible fuzzy subsets like "low", "high", "medium". Every element in these fuzzy subsets has its own degree of membership.

The main reasons for the use of fuzzy logic to voltage stability monitoring and control are

- The approach is simple, straightforward and fast, where it only needs key system variables to arrive at the solution state.

- Due to the very nature of the problem, the imprecision of the linguistic variables can easily be transferred into fuzzy domain, which would otherwise be difficult to manage.

- Fuzzy logic can handle non-linearity of power system problem and does not require complex computations as in traditional methods. Thus, it is more efficient than conventional methods for voltage stability analysis. 
In the proposed fuzzy-expert system, the key system variables like load bus voltage, generator MVAR reserve and generator terminal voltage which are used to monitor the voltage stability are stored in the database. Changes in the system operating conditions are reflected in the database. The above key variables are fuzzified using the theory of uncertainty. The rulebase comprises a set of production rules which form the basis for logical reasoning conducted by the inference engine. The production rules are expressed in the form of IF-THEN type, that relates key system variables to stability. The strength of the above fuzzy-expert system can be exploited fully when the rulebase is used in conjunction with the database.

The modal analysis technique along with continuation power flow discussed in chapter two, play an important role in the development of the proposed fuzzy-expert system. It is not a part of the fuzzy-expert system. It is used as an aid in the formulation of database and as a benchmark tool for validating the accuracy of the proposed approach.

\subsubsection{The Database}

The key variables identified are load bus voltage, generator MVAR reserve and generator terminal voltage. The three key variables are selected based on the solution obtained by repeated load flow and modal analysis performed for various operating conditions. Based on the simulations carried out for different loading factors, it is found that load bus voltage and reactive generation reserve are significantly affected as the system approaches collapse point for a specific loading pattern. Also, the terminal voltage of the generators has an effect on voltage stability margin. Hence, the above three variables are used to monitor the voltage stability of the system. 
Each of these variables is further divided into four linguistic variables and then transformed into fuzzy domain: Low, Tolerable, Moderate and Safe. The membership functions for these linguistic variables are of the general form given by

$$
\mu=\frac{1}{1+\left(\frac{\mathrm{K}-\mathrm{a}}{\mathrm{A}}\right)^{2}}
$$

where, $\mathrm{K}$ may be any one of the key variables.

$A$ and $\mathbf{a}$ are constants.

The membership functions of the key variables are shown in Fig.6.1, Fig.6.2 and Fig.6.3.

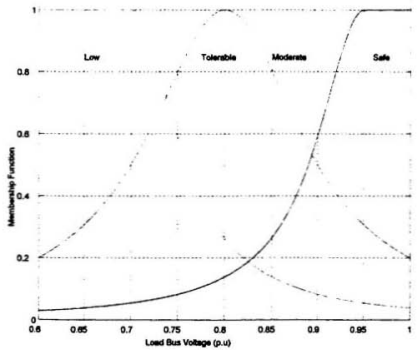

Fig.6.1 Membership function for the worst load bus voltage. 


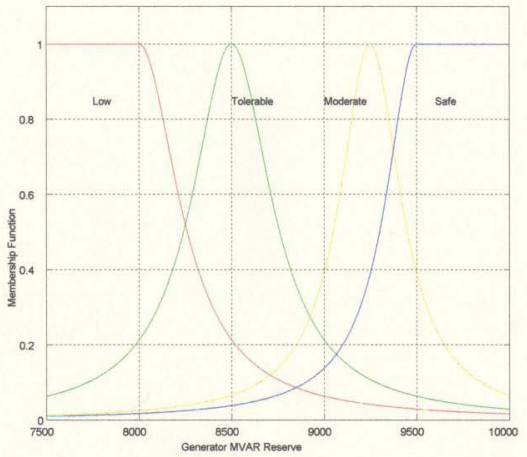

Fig.6.2 Membership function for the worst MVAR reserve. 


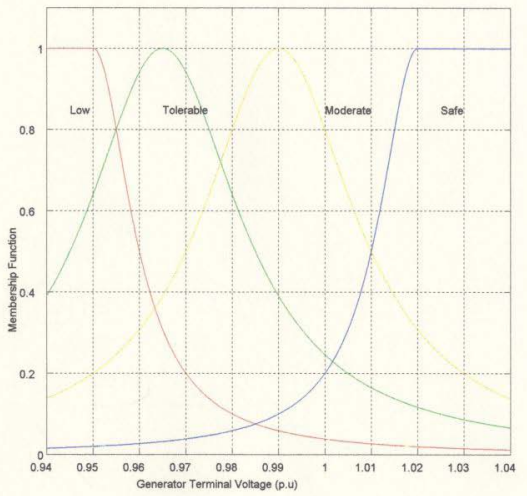

Fig.6.3 Membership function of the generator terminal voltage corresponding to the worst MVAR reserve. 
For example, in Fig.6.1 corresponding to the load bus voltage of 0.6 p.u, the fuzzy sets Low, Tolerable, Moderate and Safe have membership grades $1.0,0.2,0.1$ and 0.02 respectively. The union of the above fuzzy sets represents the total uncertainty in the stability of the system.

The membership functions of the key variables can take the form monotonic, bell-shaped, trapezoidal or even triangular. The selection of the type, depends on the application and how closely it can describe the system behavior. In the following studies that involve non-linear equations, bell-shaped coupled with S-shape is the closest that describes the behavior of power system in general. The constants " $\mathrm{a}$ " and " $\mathrm{A}$ " are selected such that the membership function covers the entire range of the key variables. For example in Fig.6.1., the membership function of the four linguistic variables should cover lower limit ( 0.6 p.u ) and upper limit ( 1.0 p.u ). Parameters " $\mathrm{a}$ " and " $\mathrm{A}$ " are selected such that the desired stability condition is satisfied for the test cases. In this way, proper membership grades are obtained. In an utility environment, the peak values of these linguistic variables of the key variable is obtained from the operator's experience [39]. In the studies supported here, peak values have been found by trial and error. Extensive simulations are performed to identify the range of key variables. The constants " $\mathrm{a}$ " and " $\mathrm{A}$ " in equation 6.1 are selected appropriately to give proper membership grades. For instance, the parameters " $\mathrm{a}$ " and " $\mathrm{A}$ " for the membership function of the worst load bus voltage, worst MVAR reserve, generator terminal voltage corresponding to the worst MVAR reserve are shown in Table 6.1. 
Table 6.1 Parameters a and $\mathrm{A}$ for the membership function of the key variables.

\begin{tabular}{|c|c|c|c|c|}
\hline & \multicolumn{4}{|c|}{ Linguistic Variables } \\
\hline & Low & Tolerable & Moderate & Safe \\
\hline \multicolumn{5}{|c|}{ For membership function of the worst load bus voltage } \\
\hline a ( p.u ) & 0.7 & 0.8 & 0.9 & 0.95 \\
\hline A ( p.u ) & 0.06 & 0.1 & 0.1 & 0.06 \\
\hline \multicolumn{5}{|c|}{ For membership function of the worst MVAR reserve } \\
\hline a (MVAR) & 8000 & 8500 & 9250 & 9500 \\
\hline A (MVAR) & 260 & 260 & 200 & 200 \\
\hline \multicolumn{5}{|c|}{ For membership function of the generator terminal voltage } \\
\hline a ( p.u ) & 0.95 & 0.965 & 0.99 & 1.02 \\
\hline A ( p.u ) & 0.01 & 0.02 & 0.02 & 0.01 \\
\hline
\end{tabular}

Having represented the inputs to the expert system as linguistic variables, the output of the expert system is the degree of voltage stability represented by four linguistic variables: Very stable (VS), stable ( $\mathrm{S}$ ), critically stable (CS) and unstable ( US ). The four linguistic variables correspond to the following situations.

$$
\begin{array}{rrrl}
\text { vS: } & \lambda>10.0 \\
\text { S: } & 10.0 \geq \lambda>6.5 \\
\text { CS: } & 6.5 \geq \lambda>2.0 \\
\text { US: } & & \lambda \leq 2.0
\end{array}
$$

where, $\lambda$ is the minimum of the absolute real part of the eigenvalues of the reduced Jacobian matrix $J_{R}$ of equation 3.7. 


\subsubsection{The Rulebase}

Two separate sets of rulebase are formed, one for monitoring and other for control stage.

\section{Monitoring stage:}

In this stage, the rule base is divided into four groups.

group 1:rules that relate worst load bus voltage to stability measure.

group 2:rules that relate key generator MVAR reserve to stability measure.

group 3:rules that relate key generator terminal voltage to stability measure.

group 4:rules that combine stability measures of the above three parameters.

Typical rule for groups 1,2 and 3 is of the form:

IF $\mathrm{K}$ is $\mathrm{X} 1$ THEN $\mathrm{S}$ is $\mathrm{X} 2$, with membership value $\mu(\mathrm{X} 1, \mathrm{X} 2)$, where

$K$ is any one of the key variables.

$\mathrm{X} 1$ is any one of the four possible fuzzy subset (low, tolerable, moderate, safe ) characterizing the key variables.

$\mathrm{S}$ is membership grade.

$\mathrm{X} 2$ is any one of the four possible fuzzy subset (VS, S, CS, US) characterizing stability measure.

There are 48 rules relating key variables to stability measure, 16 rules for each variable. Among the 16 rules, there are 4 rules which will yield $\mu$ (VS). The resultant $\mu$ (VS ) is obtained by max-min compositional rule of inference as follows 


$$
\begin{aligned}
\mu(\mathrm{VS})=\max ( & \min (\mu(\text { low }), \mu(\text { low, VS })), \\
& \min (\mu(\text { tol }), \mu(\text { tol, VS })), \\
& \min (\mu(\bmod ), \mu(\bmod , \mathrm{VS})), \\
& \min (\mu(\text { saf }), \mu(\text { saf, VS }))) .
\end{aligned}
$$

The membership values for $\mu(\mathrm{S}), \mu$ ( CS ) and $\mu$ ( US ) can be derived similarly.

For group 4, the stability measures derived for worst load bus voltage ( $\mu \mathrm{sb}$ (VS), $\mu \mathrm{sb}$ (S), $\mu \mathrm{sb}$ (CS) and $\mu \mathrm{sb}$ (US) ), worst generator MVAR reserve ( $\mu \mathrm{sm}$ (VS), $\mu \mathrm{sm}$ (S), $\mu \mathrm{sm}$ (CS) and $\mu \mathrm{sm}$ (US) ), corresponding generator terminal voltage of worst MVAR reserve ( $\mu \mathrm{sg}$ (VS), $\mu \mathrm{sg}$ (S), $\mu \mathrm{sg}$ (CS) and $\mu \mathrm{sg}$ (US) ), are combined together using max-min composition to yeild the overall stability of the power system. Thus, in this group, there are 256 rules. The stability measure with the greatest membership value gives the state of the system.

\section{Control stage:}

The procedure is exactly the same as mentioned in the monitoring stage, but the only difference is that the number of inputs to the expert system is two instead of three. Here, the generator terminal voltage is not taken as one of the key input variable because of its value being fixed throughout the control phase. This stage has 96 rules.

The reasoning process of the inference engine that involves both monitoring and control is implemented in MATLAB [40]. Appendix B shows the rules relating key variables to stability measure. Appendix C 
shows the data used for the formulation of the rulebase with reference to the monitoring stage.

\subsection{Inference Engine}

The inference engine takes the key variables such as load bus voltage, reactive generation reserve and terminal voltage of the generator as its inputs and uses the production rules to perform deductive reasoning. The steps involved in the reasoning process are shown below

\section{Monitoring stage:}

(1) Read in load bus voltage, reactive generation reserve and terminal voltage of the generator.

(2) Fuzzify each of these key elements into four linguistic variables using equation 6.1 to obtain their membership grades.

(3) Input the membership grades into the fuzzy rulebase.

(4) From the rules formed under group 1, obtain the stability measures corresponding to the worst load bus voltage.

(5) From the rules formed under group 2, obtain the stability measures corresponding to generator MVAR reserve.

(6) From the rules formed under group 3, obtain the stability measures corresponding to key generator terminal voltage.

(7) From the rules formed under group 4, evaluate the global stability membership grade of the system.

If the system state is either critically stable or unstable, then perform the control action. 


\section{Control stage:}

(8) To improve the voltage profile of the worst load bus, VAR compensation and/or raise in generator terminal voltage is performed at the existing controllers.

(9) Fuzzify these new improved values and combine with stability rules to obtain the new global stability state.

\subsection{Simulation Results and Discussions}

To show the effectiveness of the proposed fuzzy-expert system, the New England 39 bus system is taken as an example. The single line diagram of the system is shown in Fig.3.4. Here, the load is increased at buses 3, 4, $12,15,21$ and generation at buses $30,32,35$ and 37 are scaled accordingly to meet the increased demand. The simulation is carried out under six different operating conditions.

condition 1 : No contingency and generator 32 terminal voltage is maintained at 0.9831 p.u.

condition 2 : No contingency and generator 32 terminal voltage is maintained at 0.95 p.u.

condition 3 : No contingency and generator 32 terminal voltage is maintained at 1.05 p.u.

condition 4 : line $6-11$ outage.

condition 5 : generator 36 outage.

condition 6 : line $6-11$ and generator 36 outage.

To simplify the analysis, only six conditions are considered. In reality, for the proposed fuzzy-expert system to be valid, all possible conditions 
have to be taken into account. Note that some of the worst cases have been considered to validate the correctness of the proposed system. Extensive number of operating conditions are tested to verify the correctness of the expert system output during the monitoring stage. A complete list of expert system output for all cases is shown in Appendix D. Table 6.2 below shows the corresponding operating condition for the 32 cases listed in Appendix D. Each case is for a specific loading condition.

Table 6.2 Operating conditions for the 32 cases listed in Appendix D

\begin{tabular}{|c|c|}
\hline Index No & Operating Condition \\
\hline $1-7$ & 1 \\
\hline $8-10$ & 2 \\
\hline $11-17$ & 3 \\
\hline $18-22$ & 4 \\
\hline $23-28$ & 5 \\
\hline $29-32$ & 6 \\
\hline
\end{tabular}

Table 6.3 Expert system output - Monitoring

\begin{tabular}{|c|c|c|c|c|c|c|}
\hline $\begin{array}{c}\text { Index } \\
\text { No }\end{array}$ & $\begin{array}{c}\text { Gen.32 } \\
\text { Volt (p.u) }\end{array}$ & $\begin{array}{c}\text { Bus 12 } \\
\text { Load Volt } \\
\text { (p.u) }\end{array}$ & $\begin{array}{c}\text { Gen.32 } \\
\text { MVAR }\end{array}$ & $\begin{array}{c}\text { Global } \\
\text { state }\end{array}$ & $\begin{array}{c}\text { VSTAB output } \\
\text { Eigen } \\
\text { value }\end{array}$ \\
state \\
\hline \multicolumn{7}{|c|}{ NO CONTINGENCY } \\
\hline 1 & 0.9831 & 1.0072 & 9823.0 & VS & 10.11 & VS \\
\hline 2 & 0.9831 & 0.6093 & 8052.4 & US & 0.39 & US \\
\hline 3 & 0.9500 & 0.6399 & 8361.4 & US & 1.30 & US \\
\hline 4 & 1.0500 & 1.0374 & 9630.3 & VS & 10.55 & VS \\
\hline 5 & 1.0500 & 0.8263 & 8663.0 & CS & 5.10 & CS \\
\hline \multicolumn{7}{|c|}{ CONTINGNCY } \\
\hline 6 & 0.9831 & 0.9394 & 9545.8 & S & 8.30 & S \\
\hline 7 & 0.9831 & 0.6059 & 8102.4 & US & 0.06 & US \\
\hline 8 & 0.9831 & 0.8597 & 9192.6 & CS & 5.74 & CS \\
\hline 9 & 0.9831 & 0.6936 & 8450.6 & US & 1.66 & US \\
\hline 10 & 0.9831 & 0.9356 & 9530.0 & S & 7.52 & S \\
\hline 11 & 0.9831 & 0.6577 & 8324.1 & CS/US & 0.96 & US \\
\hline
\end{tabular}


For the purpose of analysis, consider the eleven cases shown in Table 6.3. The expert system output for these eleven operating cases correspond to the monitoring stage. Here, the fuzzy-expert system output (Global state ) is compared with the simulation results given by VSTAB 4.1 output through modal analysis. In Table 6.3, index Nos.1 and 2 correspond to operating condition 1 , index No. 3 refers to operating condition 2, index Nos. 4 and 5 correspond to operating condition 3, index Nos.6 and 7 correspond to operating condition 4 , index Nos.8 and 9 correspond to operating condition 5 and finally index Nos.10 and 11 correspond to operating condition 6.

As shown in Table 6.3, the input variables to the expert system are bus 12 load voltage, generator 32 MVAR reserve and generator bus 32 terminal voltage. The basis for their selection is from their participation factors described in chapter 3. Appendix $E$ shows the participation factors for the critical case ( at the voltage stability limit ) for each of those six conditions. As seen in Table 6.3, there are some operating cases that are either unstable or critically stable. These are the cases that need control.

To show the difference between conventional methods and the proposed approach, consider the index No.7 of Table 6.3. The input variables to the fuzzy-expert system are bus 12 load voltage $=0.6059$ p.u, generator 32 terminal voltage $=0.9831$ p.u, generator 32 MVAR reserve $=8102.4$ MVAR.

From Fig.6.1., the membership function of the linguistic variables - low, tolerable, moderate, safe for the worst load bus voltage are 


$$
\begin{aligned}
& \text { mub_lo }=1.0 \\
& \text { mub_tol }=0.2098 \\
& \text { mub_mod }=0.1036 \\
& \text { mub_saf }=0.0295
\end{aligned}
$$

From Fig.6.2., the membership function of the linguistic variables for the worst MVAR reserve are

$$
\begin{aligned}
& \text { muv_lo }=0.8657 \\
& \text { muv_tol }=0.2995 \\
& \text { muv_mod }=0.0295 \\
& \text { muv_saf }=0.0201
\end{aligned}
$$

From Fig.6.3., the membership function of the linguistic variables for the generator terminal voltage are

$$
\begin{aligned}
& \text { memg_lo }=0.0836 \\
& \text { memg_tol }=0.5497 \\
& \text { memg_mod }=0.8936 \\
& \text { memg_saf }=0.0684 .
\end{aligned}
$$

Once the membership function of the linguistic variables are determined, the next step is to relate these variables to the stability measure. From the rules formed under group 1 , the stability measure for the very stable (VS) case is obtained as follows

$$
\begin{aligned}
& \text { vsb1 }=\min (\text { mub_lo, murb }(4,1)) \\
& \text { vsb2 }=\min (\text { mub_tol, murb }(3,1)) \\
& \text { vsb3 }=\text { min (mub_mod, murb }(2,1)) \\
& \text { vsb4 }=\text { min (mub_saf, murb }(1,1))
\end{aligned}
$$

where, murb matrix gives the required rules relating the load bus voltage to the stability measure of group 1 as shown in Appendix B. Thus, the overall stability measure for "very stable" is given by

$$
\text { mb_vs }=\max (\text { vsbl, vsb2, vsb3, vsb4 })=0.1036
$$


Similarly, the stability measures for stable, critically stable and unstable cases are obtained as

$$
\begin{aligned}
& \text { mb_s }=0.2098 \\
& \text { mb_cs }=0.5 \\
& \text { mb_us }=1.0
\end{aligned}
$$

Following the same procedure as mentioned above, the rules for group 2 can be derived. The stability measures corresponding to key generator MVAR are

$$
\begin{aligned}
& \text { mr_vs }=0.0295 \\
& \text { mr_s }=0.2995 \\
& \text { mr_cs }=0.5 \\
& \text { mr_us }=0.8657
\end{aligned}
$$

From rules formed under group 3, the stability measures corresponding to generator terminal voltage are

$$
\begin{aligned}
& \text { mg_vs }=0.6 \\
& \mathrm{mg \_ s}=0.8936 \\
& \mathrm{mg \_ cs}=0.8936 \\
& \mathrm{mg \_ us}=0.4
\end{aligned}
$$

Finally, from the rules formed under group 4 , the stability measures of the system are

$$
\begin{aligned}
& \text { ss_vs }=0.2098 \\
& \text { ss_s }=0.4 \\
& \text { ss_cs }=0.8 \\
& \text { ss_us }=0.8657
\end{aligned}
$$

The overall system stability is given by

$$
\text { gl_sta }=\max (\text { ss_vs, ss_s, ss_cs, ss_us ) }=0.8657
$$

Hence, the system stability is unstable. 
From the above analysis, it is seen that the solution is obtained by simple max-min rules of fuzzy logic and thereby avoiding detailed computations of conventional methods.

For the purpose of control, consider the following three cases.

Case A:

In this case, it is assumed that Static Var Compensators (SVC) are available at buses $6,8,13$ with maximum capacity of 100 MVAR each, while the voltage of generators at buses 32 and 37 can be adjusted up to a maximum of 1.05 p.u.

Case B:

Here, assume improved limits on controllers in the same buses as in case A. SVC controllers at buses $6,8,13$ operate with a maximum capacity of 400 MVAR each, while the upper limit of generator voltage at buses 32 and 37 is 1.06 p.u.

\section{Case C:}

In this case, SVC controllers are available at buses $6,8,13,21$ with a maximum capacity of $400 \mathrm{MVAR}$ each, the upper limit of generator voltage at buses $30,32,35,37$ is 1.06 p.u and the upper limit of the taps of tap changing transformer in branches $12-11$ and $19-20$ is 1.07 p.u. Thus, ten controllers are considered for this case.

Table 6.4, Table 6.5 and Table 6.6 show the expert system output after the control action for those cases needing control. 
Table 6.4 Expert system output - control stage ( case A )

\begin{tabular}{|c|c|c|c|c|c|}
\hline Index No & $\begin{array}{c}\text { Bus 12 } \\
\text { Load Volt } \\
\text { (p.u) }\end{array}$ & $\begin{array}{c}\text { Gen. 32 } \\
\text { MVAR }\end{array}$ & Global & \multicolumn{2}{|c|}{ VSTAB output } \\
Eigen & $\begin{array}{c}\text { System } \\
\text { value }\end{array}$ & state \\
\hline 2 & 0.7944 & 8490.7 & CS & 4.12 & CS \\
\hline 3 & 0.8192 & 8610.5 & CS & 4.76 & CS \\
\hline$* 5$ & 0.8673 & 8843.5 & - & 6.03 & CS \\
\hline 7 & 0.8229 & 8656.3 & CS & 4.63 & CS \\
\hline 8 & 0.9349 & 9176.7 & S & 7.11 & S \\
\hline 9 & 0.8307 & 8682.6 & CS & 4.44 & CS \\
\hline$* 11$ & 0.8362 & 8720.4 & - & 4.48 & CS \\
\hline
\end{tabular}

* misclassification

Table 6.5 Expert system output - control stage ( case B )

\begin{tabular}{|c|c|c|c|c|c|}
\hline \multirow[t]{2}{*}{ Index No } & \multirow{2}{*}{$\begin{array}{c}\text { Bus } 12 \\
\text { Load Volt } \\
\text { (p.u) }\end{array}$} & \multirow{2}{*}{$\begin{array}{l}\text { Gen. } 32 \\
\text { MVAR }\end{array}$} & \multirow{2}{*}{$\begin{array}{l}\text { Global } \\
\text { state }\end{array}$} & \multicolumn{2}{|c|}{ VSTAB output } \\
\hline & & & & $\begin{array}{l}\text { Eigen } \\
\text { value }\end{array}$ & $\begin{array}{c}\text { System } \\
\text { state }\end{array}$ \\
\hline 2 & 0.9179 & 8988.1 & - & 6.74 & $\mathrm{~S}$ \\
\hline 3 & 0.9336 & 9067.5 & VS/S & 7.2 & $\mathrm{~S}$ \\
\hline 5 & 0.9671 & 9234.5 & $\mathrm{~S}$ & 8.19 & $\mathbf{S}$ \\
\hline 7 & 0.9325 & 9087.8 & $\mathrm{~S}$ & 7.2 & $\mathbf{S}$ \\
\hline 8 & 0.9349 & 9176,7 & S & 7.11 & S \\
\hline 9 & 0.9475 & 9147.7 & $\mathrm{~S}$ & 6.79 & $\mathbf{S}$ \\
\hline 11 & 0.9443 & 9145.5 & $\mathrm{~S}$ & 6.83 & $\mathbf{S}$ \\
\hline
\end{tabular}

* misclassification 
Table 6.6 Expert system output - control stage ( case C )

\begin{tabular}{|c|c|c|c|c|c|}
\hline \multirow[t]{2}{*}{ Index No } & \multirow{2}{*}{$\begin{array}{c}\text { Bus } 12 \\
\text { Load Voit } \\
\text { (p.u) }\end{array}$} & \multirow{2}{*}{$\begin{array}{l}\text { Gen } 32 \\
\text { MVAR }\end{array}$} & \multirow{2}{*}{$\begin{array}{l}\text { Global } \\
\text { state }\end{array}$} & \multicolumn{2}{|c|}{ VSTAB output } \\
\hline & & & & $\begin{array}{l}\text { Eigen } \\
\text { value }\end{array}$ & $\begin{array}{c}\text { System } \\
\text { state }\end{array}$ \\
\hline 2 & 0.9620 & 9060.8 & VS/S & 7.44 & s \\
\hline 3 & 0.9768 & 9133.7 & $\mathbf{s}$ & 7.86 & S \\
\hline 5 & 1.0092 & 9292.0 & $\mathbf{S}$ & 8.78 & $\mathbf{S}$ \\
\hline 7 & 0.9744 & 9148.4 & $\mathbf{S}$ & 7.77 & $\mathbf{S}$ \\
\hline 98 & 1.0656 & 9566.3 & VS & 9.47 & 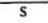 \\
\hline 9 & 0.9921 & 9217.9 & $\mathbf{S}$ & 7.52 & $\mathbf{S}$ \\
\hline 11 & 0.9879 & 9211.7 & $\mathbf{S}$ & 7.5 & $\mathbf{S}$ \\
\hline
\end{tabular}

* misclassification

It can be seen from Tables 6.4 to 6.6 that the global state of the system has changed after the control action. For example, in case $C$, the operating condition corresponding to index number 9 is unstable (US) before the control action and stable after the control action. Note that the output of the expert system is either very stable or stable for the operating condition corresponding to the index 2 . This is a typical case where, the expert system is able to come out with an approximate solution only, considering the fact that no solution may be possible by other conventional methods under similar circumstances.

Note: The term "misclassification" refers to the error in the classification state by the fuzxy-expert system output. The four classification states are Very Stable, Stable, Critically Stable and Unstable. If there is a discrepancy between the fizzy-expert system output (Global state ) and the system state of the VSTAB output, then a "misclassification" is said to oceur. 
From the above Tables, it is seen that there is a considerable improvement in the voltage stability margin of the system, limited only by the number of controllers available and their operational limits. Voltage stability margin ( VSM) is a measure of how close the system is to voltage instability. It is defined as the difference between the values of a Key System Parameter ( KSP) at the current operating condition and the voltage stability critical point [17]. Here, KSP is defined as the total load increase in the selected buses. Fig. 6.4 shows the voltage stability margin improvement after the control action for the cases A, B and C. Table 6.7 shows the voltage stability margin corresponding to Fig. 6.4.

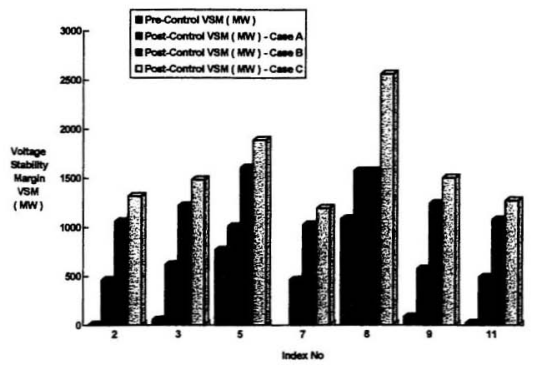

Fig. 6.4 Voltage stability margin (VSM) for pre and post control cases 
Table 6.7 Voltage Stability Margin ( VSM) for pre and post control cases

\begin{tabular}{|c|c|c|c|c|c|}
\hline $\begin{array}{c}\text { Case } \\
\text { No }\end{array}$ & $\begin{array}{c}\text { Total Load at } \\
\text { Selected Buses } \\
\text { (MW ) }\end{array}$ & $\begin{array}{c}\text { Pre-Control } \\
\text { VSM } \\
\text { (MW ) }\end{array}$ & \multicolumn{4}{|c|}{ Post-Control VSM ( MW ) } \\
\hline 2 & 4971.4 & 5.4 & 461.5 & 1059.7 & 1318.4 \\
\hline 3 & 4812.0 & 53.7 & 620.0 & 1219.1 & 1483.8 \\
\hline 5 & 4424.5 & 768.7 & 1008.4 & 1606.6 & 1888.1 \\
\hline 7 & 4253.2 & - & 463.3 & 1027.1 & 1193.4 \\
\hline 8 & 3424.5 & 1085.5 & 1574.6 & 1574.6 & 2559.4 \\
\hline 9 & 4424.5 & 85.5 & 574.6 & 1243.0 & 1504.3 \\
\hline 11 & 4124.5 & 23.1 & 492.6 & 1079.3 & 1273.1 \\
\hline
\end{tabular}

From the above simulation results, it is seen that given the key variables ( load bus voltage, generator MVAR reserve and generator terminal voltage ), the expert system arrives at the global state without the need for complex computations.

With reference to the selection of the number of input variables on the size and complexity of fuzzy-expert system, consider the monitoring stage of the proposed expert system. Here, three input variables are selected. The total number of rules under the four groups is 304 . If only two input variables are selected, the number of rules is reduced to 96 . Thus, the size of the rules will have an effect on the computational complexity of the fuzzy-expert system.

The designed expert system is tested for a total of 68 cases covering a wide range of operating conditions. 32 cases are listed under Appendix D, 21 cases listed in the control stages - Case A, Case B and Case C, 15 cases 
listed under Appendix C, totalling 68 cases. Out of these 68 cases, 4 cases are misclassified.

The source of error for the misclassified cases is probably due to the inadequate fuzzy-expert system framework. Within this framework, two key factors are the membership function of the key variables and inappropriate membership value assigned to the linguistic variables describing the imprecision of the rule. Since the membership function of the key variables described by the equation 6.1 is formed based on the extensive simulations, the only other parameter responsible for the misclassification is the latter. For example, consider the operating case corresponding to the index No. 5 of Table 6.4. The input variables to the fuzzy-expert system are bus 12 load voltage $=0.8673$ p.u and generator 32 MVAR reserve $=8843.5$ MVAR. From Fig.6.1. and applying max-min compositional rule of inference, the membership function of the stability measures VS, S, CS and US for the load bus voltage are

$$
\begin{aligned}
& \mathrm{ml}-\mathrm{vs}=0.6 \\
& \mathrm{ml}-\mathrm{s}=0.9034 \\
& \mathrm{ml}-\mathrm{cs}=0.6882 \\
& \mathrm{ml}-\mathrm{us}=0.4
\end{aligned}
$$

Similarly, from Fig.6.2 and applying max-min compositional rule of inference, the membership function of the stability measures VS, S, CS and US for the generator MVAR reserve are

$$
\begin{aligned}
& \mathrm{mg}-\mathrm{vs}=0.1948 \\
& \mathrm{mg}-\mathrm{s}=0.3642 \\
& \mathrm{mg}-\mathrm{cs}=0.3642 \\
& \mathrm{mg} \text {-us }=0.3642
\end{aligned}
$$


The rules relating load bus voltage, generator MVAR reserve and stability measure is given by the "mugl" matrix as shown below

$$
\text { mugl }=\left[\begin{array}{llll}
1.0 & 0.5 & 0.4 & 0.0 \\
0.8 & 1.0 & 0.4 & 0.0 \\
0.5 & 1.0 & 0.7 & 0.0 \\
0.0 & 0.4 & 1.0 & 0.8 \\
0.6 & 1.0 & 0.5 & 0.0 \\
0.2 & 0.6 & 0.5 & 0.0 \\
0.5 & 0.6 & 0.7 & 0.0 \\
0.0 & 0.5 & 1.0 & 0.8 \\
0.5 & 1.0 & 0.8 & 0.2 \\
0.0 & 0.6 & 1.0 & 0.65 \\
0.5 & 0.6 & 1.0 & 0.2 \\
0.0 & 0.3 & 1.0 & 0.7 \\
0.0 & 0.2 & 1.0 & 0.8 \\
0.0 & 0.6 & 0.8 & 1.0 \\
0.0 & 0.2 & 0.8 & 1.0 \\
0.0 & 0.2 & 0.5 & 1.0
\end{array}\right]
$$

From the above matrix, the stability measures for the entire system are

$$
\begin{aligned}
& \text { ss-vs }=0.3642 \\
& \text { ss-s }=0.3642 \\
& \text { ss-cs }=0.3642 \\
& \text { ss-us }=0.3642
\end{aligned}
$$

From the above solution, one cannot infer whether the system is very stable, stable, critically stable or unstable. For the above operating condition, the fuzzy-expert system did not arrive at the proper solution.

The fuzzy-expert system output is significantly influenced by the "mugl" matrix. The membership values in the "mugl" matrix describes the 
imprecision of the rules and is obtained by trial and error method. In actual field situation, the "mugl" matrix is formed through operator experience. Hence, the projected $10 \%$ classification error may not be taken as a sole criteria for the proposed fuzzy-expert system to be acceptable in a field situation.

The limitations of the proposed fuzzy-expert system in accurately classifying the voltage stability condition are

- The size of the rulebase is large due to the selection of three input variables for the monitoring stage and two input variables for the control stage. The total number of rules for the above two stages is 400 .

- The viability of the proposed fuzzy-expert system in an actual field situation is questionable due to the projected $10 \%$ classification error and non-availability of improvement in the computational speed compared to the conventional voltage stability methods.

- $\quad$ The proposed fuzzy-expert system assumes a constant power load model and test results limited to sixty four operating conditions. To make a proper voltage stability assessment for a practical power system, suitable load models have to be incorporated.

Initially, the knowledge-base of fuzzy-expert system starts with 15 operating cases as indicated in Appendix C. Once the data used for the formation of the rulebase is established, the 32 cases listed in Appendix D are tested. The fuzzy-expert system updates its knowledge-base to 47 cases and so on. Each time a new operating case is tested and verified, it is stored in the knowledge-base and thereby its performance can be improved. In a utility operation, the true potential of the proposed fuzzy- 
expert system with its vast knowledge-base can be realized fully only after a considerable period of time and experience.

It is possible to investigate the optimum selection of the number of key variables for evaluating the voltage stability of any complex power system under "any operating condition", if sufficient resources and system data are available. In order to establish firm conclusions based on the concepts developed in the preceding chapters, extensive simulations on various power utility systems need to be performed, and factors that affect the performance of fuzzy-expert system identified. In the studies reported in this thesis, only limited number of cases were tested on the sample New England 39 bus system because of non-availability of resources and real utility system data.

\subsection{Integration of fuzzy-expert system into an Energy Management System}

The main challenge for the implementation of an on-line voltage stability evaluation in Energy Management System ( EMS ) is the computational burden and the ability to arrive at the operating state of the system. Also, it is essential for the operator to have a clear knowledge of the operating state when the power system is operating close to its limits. This is where the fuzzy-expert system plays an important role. Since, the proposed fuzzy- expert system uses input parameters already monitored by the EMS, additional data acquisition equipment and other associated communication systems become unnecessary. Hence, speed can be improved considerably. 
To design an efficient fuzzy-expert system, key variables that affect the system voltage stability have to be identified first either by off-line simulations or through operator's experience. In order to establish database that reflects all possible operating conditions of the system, numerous simulations are to be performed and verified by a standard bench mark tool. A set of decision rules relating key system variables to stability are formed. This is a continuous process wherein the fuzzy-expert system updates its knowledge-base and thereby improve its performance. Fig 6.5 shows a block diagram of the proposed scheme integrating fuzzyexpert system for voltage stability evaluation as part of an Energy Management System.

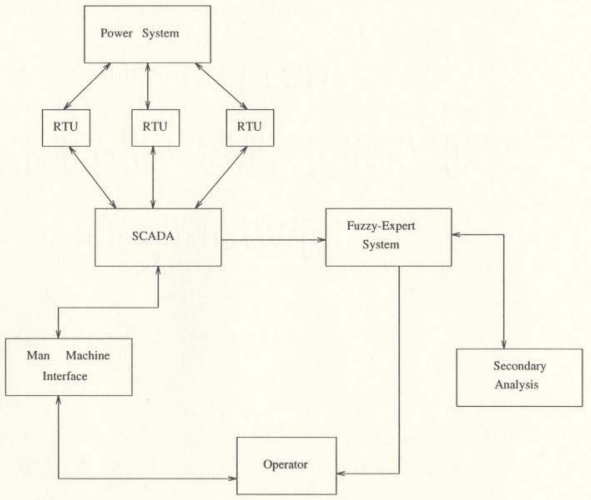

Fig 6.5 Fuzzy-expert system as a part of new EMS 
The Remote Terminal Units (RTUs) collect data from various locations in the power system and relay them to the Supervisory Control and Data Acquisition (SCADA). The SCADA is connected to the Man Machine Interface (MMI), which allows the operator to interact with the EMS. The fuzzy-expert system gets its inputs from the SCADA. The main function of the SCADA is to perform various control actions like switching on and off of circuit breaker, transformer taps, capacitor banks etc. Based on the production rules developed which form the basis for logical reasoning conducted by the inference engine, the expert system arrives at the system state and alerts the system operator to any potentially dangerous situations. Before taking the control action, the operator performs the load flow solution by incorporating appropriate VAR compensation or other available control devices in the secondary analysis to obtain improved load bus voltage and reactive generation reserve. The secondary analysis contains application functions like contingency analysis, load flow, shortcircuit analysis, stability analysis and optimal power flow. When the operator is satisfied with the secondary analysis output, the improved load bus voltage and reactive generation reserve serve as input to the SCADA after verifying the system state from the fuzzy-expert system output. The SCADA takes the necessary control action to alleviate the voltage stability problem.

The proposed fuzzy-expert system does not replace any of the well developed algorithmic solutions of the secondary analysis. However, it offers a powerful and effective tool for the use of these programs. 


\subsection{Summary}

This chapter addresses the issues concerning the selection of the number of input variables and its impact on the size and complexity of the fuzzy-expert system. It also includes factors to be taken into account for proper selection of parameters " $\mathrm{a}$ " and " $\mathrm{A}$ " of the generic equation describing the membership functions of the key variables. Issues like accuracy of the method and errors are also addressed. It also substantiates the claims for the use of fuzzy logic approach by showing a reliable assessment of stability for the monitoring stage without performing the detailed voltage stability calculations for a given operating point.

In the proposed fuzzy-expert system, the key variables like load bus voltage, generator MVAR reserve and generator terminal voltage which are used to monitor the voltage stability are stored in the database. Changes in the system operating conditions are reflected in the database. The rulebase comprises a set of production rules which form the basis for logical reasoning conducted by the inference engine. The reasoning process of the inference engine is implemented in MATLAB.

Given the key variables, the expert system arrives at the global state without the need for complex computations. The New England 39 bus system is taken as a case study to illustrate the proposed procedure. Extensive operating conditions have been tested to validate the proposed system. The results that are being compared are the fuzzy-expert system output ( global state ) and the system state of the VSTAB output for the 68 operating cases. The misclassification is found to be less than $10 \%$. Hence, it has the potential to be integrated for on-line implementation in 
Energy Management System. In this new system, the membership functions of the key variables and the rulebase may be defined based on system requirements and operator's experience. Thus, it offers flexibility and satisfactory results in a very efficient way. 


\section{Chapter 7}

\section{CONCLUSIONS}

\subsection{Contribution of the Research}

The concept of voltage stability phenomena in power systems has been thoroughly reviewed. As power systems continue to be loaded closer to their stability limit, there is a need for suitable voltage stability indices.

Three simple stability indices were investigated with the help of a sample $S$ bus power system. They are singular value decomposition, " $\mathrm{L}$ " Index and QV curves. The simulation results showed that singular value decomposition and " $\mathrm{L}$ " Index indicate proximity or nearness to the voltage collapse point. But the constraint in these indices is that the load flow solution does not converge at the bifurcation point. Regarding QV curves, the method artificially stresses a single bus, hence conclusions should be confirmed by more realistic methods. Also, the curves are obtained by a series of power flow simulations that make it more time consuming.

Modal analysis technique in conjunction with continuation power flow, which is a better performance criteria for the assessment of voltage stability was investigated. Simulations were carried out for the IEEE 30 bus system and the New England 39 bus system. The above two examples indicate how modes represent areas prone to voltage instability. Thus, modal analysis clearly identifies groups of buses and critical bus that participate in the instability and thereby eliminate the problems associated with traditional methods. Though time consuming, this method is used as 
a benchmark for developing an expert system for voltage stability evaluation.

Expert systems, a subset of artificial intelligent system, have attracted wide spread interest to power system applications. This is due to their ability to handle stressed power systems and improve speed. In this regard, the concept of fuzzy-expert systems has been described in detail. A modified IEEE 30 bus system applied to voltage control was simulated to emphasize the concepts developed in the fuzzy-expert systems. To further explore its suitability to voltage stability monitoring and control, the New England 39 bus system was taken as case study. Extensive operating conditions were tested to validate the proposed scheme. The percentage error was found to be less than $10 \%$. Based on the simulation results, this new approach was found to be simple and straight forward, where it only needs key system variables to arrive at the solution state. In general, the method is able to handle non-linearity of power system problem and does not require complex computations as in traditional methods. Thus, it is more efficient than conventional methods for voltage stability analysis.

The proposed fuzzy-expert system was tested for 68 different operating conditions. Four cases were misclassified totally and three cases partially misclassified. The source of error for these misclassified cases was probably due to the inappropriate values assigned to the linguistic variables of the key variables in the rulebase of group 4. To give a guarantee or bound on the error with this method, all possible operating cases are to be tested and verified with standard bench mark tool. With the three input variables, the total number of rules for the monitoring stage was determined to be 304 . The size of the rulebase can be reduced to 96 
if two input variables are selected judicially. Thus, the size of the rulebase will have an effect on the computational complexity of the fuzzy-expert system.

There is considerable interest among utilities in developing on-line voltage stability tools that will enable the power systems to be operated at higher loads without risking voltage collapse. The fuzzy-expert system proposed in this thesis has the potential to be integrated for on-line implementation in Energy Management System to achieve the goals of secure power system operation. This will allow power system operators to continuously monitor the system state and thereby obviate any impending dangers of voltage collapse. However, to realize this challenge, an efficient database that reflects all possible system operating conditions should be formed.

\subsection{Recommendations for Future Work}

The voltage stability analysis considered in this thesis assume a constant power load model, which is not the case with a practical power system. Suitable load models can be incorporated in the stability assessment. The present study is limited to around sixty four operating conditions. To assess the viability of fuzzy-expert systems to a larger realistic power systems, all possible operating conditions should be considered. In order to enhance the efficiency of the present fuzzy-expert system, better fuzzy models and rulebase that describe both monitoring and control under one umbrella is recommended. 


\section{REFERENCES}

[1] IEEE Special Publication 90TH0358-2-PWR, Voltage Stability of Power Systems: Concepts, Analytical Tools and Industry Experience, 1990.

[2] B. Jeyasurya, Artificial neural networks for power system steady-state voltage instability evaluation, Electric Power Systems Research, 29 (1994) 85-90.

[3] A.R. Bergen, Power System Analysis, Prentice-Hall, Englewood Cliffs, NJ, 1986.

[4] C.W. Taylor, Power System Voltage Stability, McGraw-Hill, 1994.

[5] P. Kundur, Power System Stability and Control, McGraw-Hill, 1994.

[6] IEEE Special Publication 93TH0620-5-PWR, Suggested Techniques for Voltage Stability Analysis, 1993.

[7] A. Tiranuchit and R.J. Thomas, "A Posturing Strategy Against Voltage Instabilities in Electric Power Systems", IEEE Trans. Power Systems, Vol. 3, No. 1, February 1988, pp. 87-93.

[8] P. Kessel and H. Glavitsch, "Estimating the Voltage Stability of a Power System", IEEE Trans. Power Delivery, Vol. PWRD-1, No. 3, July 1986, pp. 346-354.

[9] Voltage Stability Analysis Program - VSTAB Version 4.1, Powertech Labs Inc., B.C, Canada, November 1994.

[10] G.W. Stagg and A.H. El-Abiad, Computer Methods in Power Systems Analysis, McGraw-Hill International, 1968.

[11] C.A. Canizares, A.C.Z. de Souza and V.H. Quintana, "Comparison of Performance Indices for Detection of Proximity to Voltage Collapse", IEEE Trans. Power Systems, Vol. 11, No. 3, August 1996, pp. 1441-1450. 
[12] T.J. Overbye and C.L. DeMarco, "Voltage Security Enhancement using Energy Based Sensitivities", IEEE Trans. Power Systems, Vol. 6, No. 3, August 1991, pp. 1196-1202.

[13] M. Huneault, C. Rosu, R. Manoliu and F.D. Galiana, "A Study of Knowledge Engineering Tools in Power Engineering Application", IEEE Trans. Power Systems, Vol. 9, No. 4, November 1994, pp. 1825-1832.

[14] Z.Z. Zhang, G.S. Hope and O.P. Malik, "Expert Systems in Electric Power Systems- A Bibliographical Survey", IEEE Trans. Power Systems, Vol. 4, No. 4, October 1989, pp. 1355-1361.

[15] Extended Transient/Midterm Stability Program - ETMSP Version 3.1, Ontario Hydro, Ontario, Canada, May 1994.

[16] B. Gao, G.K. Morison and P. Kundur, "Voltage Stability Evaluation using Modal Analysis", IEEE Trans. Power Systems, Vol. 7, No. 4, November 1992, pp. 1529-1542.

[17] B. Gao, G.K. Morison and P. Kundur, "Towards the Development of a Systematic Approach for Voltage Stability Assessment of Large-Scale Power Systems", IEEE Trans. Power Systems, Vol. 11, No. 3, August 1996, pp. 1314-1324.

[18] Interactive Power Flow-IPFLOW Version 4.1, Powertech Labs Inc., B.C, Canada, May 1994.

[19] V. Ajjarapu and C. Christy, "The Continuation Power Flow: A Tool for Steady-State Voltage Stability Analysis", IEEE Trans. Power Systems, Vol. 7, No. 1, February 1992, pp. 416-423.

[20] H.B. Wan, Y.H. Song and A.T. Johns, "Effective Control for Power System Voltage Stability Enhancement", 28th North American Power Symposium, M.I.T, November 1996, pp. 257-263.

[21] J. Giarratano and G. Riley, Expert Systems: Principles and Programming, PWS Publishing Company, Boston, 1994. 
[22] L.A. Zadeh, "A Theory of Approximate Reasoning", Machine Intelligence, 9, ed. J.E. Hayes, D. Michie and L.I. Mikulich, 1979, pp. 149-194.

[23] $A B B$ leads the way with solutions for total systems integration, $A B B$ Systems Control, Marketing Department, Santa Clara, CA 95051.

[24] Proceedings of Third Symposium on Expert Systems Applications to Power Systems, Japan, April 1991.

[25] K. Tomsovic and J.M. Ling, "A Proposed Fuzzy Information Approach to Power System Security", Proceedings of Third Symposium on Expert Systems Applications to Power Systems, Japan, April 1991, pp. 427-432.

[26] T. Maekawa, K. Yasuda, R. Yokoyama, H. Ohtsuki and Y. Mizukami, "Fuzzy Coordination of Multi-Objectives Reflecting Operator's Intention for Dynamic Generation Rescheduling", Proceedings of Third Symposium on Expert Systems Applications to Power Systems, Japan, April 1991, pp. 470-477.

[27] K. Tomsovic, "A Fuzzy Linear Programming Approach to the Reactive Power/Voltage Control Problem", IEEE Trans. Power Systems, Vol. 7, No. 1, February 1992, pp. 287-293.

[28] H. Mori and H. Kobayashi, "Optimal Fuzzy Inference for Short-term Load Forecasting", IEEE Trans. Power Systems, Vol. 11, No. 1, February 1996, pp. 390-396.

[29] Rahul Khare and R.D. Christie, "Prioritizing Emergency Control Problems with Fuzzy Set Theory", IEEE/PES Summer Meeting, Denver, August 1996.

[30] V.C. Ramesh and Xuan Li, "A Fuzzy Multiobjective Approach to Contingency Constrained OPF", IEEE/PES Summer Meeting, Denver, August 1996. 
[31] J.A. Momoh, X.W. Ma and K. Tomsovic, "Overview and Literature Survey of Fuzzy Set Theory in Power Systems", IEEE Trans. Power Systems, Vol. 10, No. 3, August 1995, pp. 1676-1690.

[32] T. Niimura, Y. Nakanishi, K. Yasuda and R. Yokoyama, "Multi-Attribute Voltage-Reactive Power Control Based on Approximate Reasoning", Proceedings of Third Symposium on Expert Systems Applications to Power Systems, Japan, April 1991, pp. 462-469.

[33] K.H. Abdul-Rahman and S.M. Shahidehpour, "A Fuzzy-Based Optimal Reactive Power Control", IEEE Trans. Power Systems, Vol. 8, No. 2, May 1993, pp. 662-670.

[34] A.G. Exposito, J.L.M. Ramos, J.L.R. Macias and Y.C. Salinas, "Sensitivity - Based Reactive Power Control for Voltage Profile Improvement", IEEE Trans. Power Systems, Vol. 8, No. 3, August 1993, pp. 937-945.

[35] W.R. Wagner, A. Keyhani, S. Hao and T.C. Wong, "A Rule Based Approach to Decentralized Voltage Control", IEEE Trans. Power Systems, Vol. 5, No. 2, May 1990, pp. 643-651.

[36] Ching-Tzong Su and Chien-Tung Lin, "A New Fuzzy Control Approach to Voltage Profile Enhancement for Power Systems", IEEE Trans. Power Systems, Vol. 11, No. 3, August 1996, pp. 1654-1659.

[37] Chen-Ching Liu and Kevin Tomsovic, "An Expert System Assisting Decision-Making of Reactive Power/Voltage Control", IEEE Trans. Power Systems, Vol. 1, No. 3, August 1986, pp. 195-201.

[38] R. Mohamedi, C. Belhadji, S. Lefebvre and Xuan-Dai Do, "An Expert System for Steady-State Voltage Stability", Canadian Conference for Electrical and Computer Engineering, Halifax, September 1994, pp. 696701. 
[39] Yuan-Yih Hsu and Chung-Ching Su, "A Rule-Based Expert System for Steady-State Stability Analysis", IEEE Trans. Power Systems, Vol. 6, No. 2, May 1991, pp. 771-777.

[40] MATLAB Version 4.l, The MathWorks Inc., Natick, Massachusetts 01760 , August 1992. 


\section{APPENDIX - A}

\section{Line and Bus data for the 5 bus system}

Table. A1 Line data for the 5 bus system

\begin{tabular}{|c|c|c|}
\hline $\begin{array}{c}\text { Bus } \\
\text { Code }\end{array}$ & $\begin{array}{c}\text { Line Impedance } \\
\text { ( ohm ) }\end{array}$ & $\begin{array}{c}\text { Line Charging } \\
\text { Admittance ( mho })\end{array}$ \\
\hline $1-2$ & $0.02+j 0.06$ & $\mathrm{j} 0.030$ \\
\hline $1-3$ & $0.08+\mathrm{j} 0.24$ & $\mathrm{j} 0.025$ \\
\hline $2-3$ & $0.06+\mathrm{j} 0.18$ & $\mathrm{j} 0.020$ \\
\hline $2-4$ & $0.06+\mathrm{j} 0.18$ & $\mathrm{j} 0.020$ \\
\hline $2-5$ & $0.04+\mathrm{j} 0.12$ & $\mathrm{j} 0.015$ \\
\hline $3-4$ & $0.01+\mathrm{j} 0.03$ & $\mathrm{j} 0.010$ \\
\hline $4-5$ & $0.08+\mathrm{j} 0.24$ & $\mathrm{j} 0.025$ \\
\hline
\end{tabular}

Table. A2 Bus data for the 5 bus system

\begin{tabular}{|c|c|c|c|c|c|}
\hline \multirow{2}{*}{$\begin{array}{c}\text { Bus } \\
\text { Code }\end{array}$} & \multirow{2}{*}{$\begin{array}{c}\text { Assumed } \\
\text { Bus Voltage } \\
\text { (p.u) }\end{array}$} & \multicolumn{2}{|c|}{ Generation } & \multicolumn{2}{|c|}{ Load } \\
\hline & & Mw & MVAR & MW & MVAR \\
\hline 1 & 1.06 & 0 & 0 & 0 & 0 \\
\hline 2 & 1.0 & 40 & 30 & 20 & 10 \\
\hline 3 & 1.0 & 0 & 0 & 45 & 15 \\
\hline 4 & 1.0 & 0 & 0 & 40 & 5 \\
\hline 5 & 1.0 & 0 & 0 & 60 & 10 \\
\hline
\end{tabular}




\section{APPENDIX - B}

Rules relating key variables to stability measure

\section{of the New England 39 bus system}

Table. B1 Rules relating worst load bus voltage to stability measure under group 1

\begin{tabular}{|c|c|c|c|c|}
\hline$\mu$ & VS & S & CS & US \\
\hline Safe & 1.0 & 0.8 & 0.3 & 0.0 \\
\hline Moderate & 0.6 & 1.0 & 0.4 & 0.0 \\
\hline Tolerable & 0.0 & 0.7 & 1.0 & 0.4 \\
\hline Low & 0.0 & 0.2 & 0.5 & 1.0 \\
\hline
\end{tabular}

Table. B2 Rules relating key generator MVAR reserve to stability measure under group 2

\begin{tabular}{|c|c|c|c|c|}
\hline$\mu$ & VS & S & CS & US \\
\hline Safe & 1.0 & 0.8 & 0.3 & 0.0 \\
\hline Moderate & 0.6 & 1.0 & 0.4 & 0.0 \\
\hline Tolerable & 0.0 & 0.7 & 1.0 & 0.4 \\
\hline Low & 0.0 & 0.2 & 0.5 & 1.0 \\
\hline
\end{tabular}

Table. B3 Rules relating key generator terminal voltage to stability measure under group 3

\begin{tabular}{|c|c|c|c|c|}
\hline$\mu$ & VS & S & CS & US \\
\hline Safe & 1.0 & 0.8 & 0.3 & 0.0 \\
\hline Moderate & 0.6 & 1.0 & 0.9 & 0.0 \\
\hline Tolerable & 0.0 & 0.7 & 1.0 & 0.4 \\
\hline Low & 0.0 & 0.2 & 0.5 & 1.0 \\
\hline
\end{tabular}


Table. B4 Rules relating combined key variables to stability measure under group 4

\begin{tabular}{|c|c|c|c|c|}
\hline$\mu$ & vs & $\mathbf{S}$ & CS & US \\
\hline (VS,VS,VS) & 1.0 & 0.0 & 0.0 & 0.0 \\
\hline (VS,VS,S ) & 0.6 & 0.0 & 0.0 & 0.0 \\
\hline (VS,VS,CS) & 1.0 & 0.0 & 0.0 & 0.0 \\
\hline (VS,VS,US) & 1.0 & 0.0 & 0.0 & 0.0 \\
\hline ( VS,S,VS ) & 0.8 & 0.5 & 0.0 & 0.0 \\
\hline (VS,S,S ) & 0.6 & 0.5 & 0.0 & 0.0 \\
\hline (VS,S,CS) & 0.8 & 1.0 & 0.0 & 0.0 \\
\hline (VS,S,US) & 0.8 & 1.0 & 0.0 & 0.0 \\
\hline (VS,CS,VS) & 0.0 & 0.2 & 10 & 0.8 \\
\hline (VS,CS,S) & 0.0 & 0.2 & 1.0 & 0.6 \\
\hline (VS,CS,CS) & 0.0 & 0.2 & 1.0 & 0.6 \\
\hline (VS,CS,US) & 0.0 & 0.2 & 1.0 & 0.8 \\
\hline (VS,US,VS) & 0.0 & 0.4 & 0.6 & 1.0 \\
\hline (VS,US,S) & 0.0 & 0.4 & 0.6 & 10 \\
\hline (VS,US,CS) & 0.0 & 0.4 & 0.6 & 1.0 \\
\hline (VS,US,US) & 0.0 & 0.4 & 0.6 & 1.0 \\
\hline (S,VS,VS) & 0.7 & 0.5 & 0.0 & 0.0 \\
\hline$(\mathrm{S}, \mathrm{VS}, \mathrm{S})$ & 0.6 & 0.5 & 0.0 & 0.0 \\
\hline (S,VS,CS) & 1.0 & 0.8 & 0.0 & 0.0 \\
\hline (S,VS,US ) & 1.0 & 0.8 & 0.0 & 0.0 \\
\hline (S,S,VS) & 0.0 & 0.5 & 0.0 & 0.0 \\
\hline (S,S,S ) & 0.0 & 0.5 & 0.0 & 0.0 \\
\hline (S,S,CS) & 0.0 & 1.0 & 0.0 & 0.0 \\
\hline (S,S,US) & 0.0 & 1.0 & 0.0 & 0.0 \\
\hline (S,CS,VS) & 0.0 & 0.2 & 1.0 & 0.9 \\
\hline$(\mathrm{S}, \mathrm{CS}, \mathrm{S})$ & 0.0 & 0.2 & 1.0 & 0.6 \\
\hline (S,CS,CS ) & 0.0 & 0.2 & 1.0 & 0.6 \\
\hline
\end{tabular}




\begin{tabular}{|c|c|c|c|c|}
\hline (S,CS,US) & 0.0 & 0.2 & 1.0 & 0.9 \\
\hline ( S,US,VS ) & 0.0 & 0.2 & 0.6 & 1.0 \\
\hline$(\mathrm{S}, \mathrm{US}, \mathrm{S})$ & 0.0 & 0.2 & 0.6 & 1.0 \\
\hline$(\mathrm{S}, \mathrm{US}, \mathrm{CS})$ & 0.0 & 0.2 & 0.6 & 1.0 \\
\hline ( S,US,US) & 0.0 & 0.2 & 0.6 & 1.0 \\
\hline (CS,VS,VS) & 0.0 & 10 & 0.8 & 0.5 \\
\hline (CS,VS,S) & 0.0 & 1.0 & 0.8 & 0.5 \\
\hline (CS,Vs,CS) & 0.0 & 1.0 & 0.8 & 0.5 \\
\hline (CS,VS,US) & 0.0 & 1.0 & 0.8 & 0.5 \\
\hline ( CS,S,VS ) & 0.0 & 0.4 & 1.0 & 0.8 \\
\hline$(\mathrm{CS}, \mathrm{S}, \mathrm{S})$ & 0.0 & 0.4 & 1.0 & 0.6 \\
\hline (CS,S,CS) & 0.0 & 0.4 & 1.0 & 0.6 \\
\hline (CS,S,US) & 0.0 & 0.4 & 1.0 & 0.8 \\
\hline (CS,CS,VS) & 0.0 & 0.0 & 1.0 & 0.0 \\
\hline ( CS,CS,S ) & 0.0 & 0.0 & 10 & 0.0 \\
\hline$(\mathrm{CS}, \mathrm{CS}, \mathrm{CS})$ & 0.0 & 0.0 & 1.0 & 0.0 \\
\hline$(\mathrm{CS}, \mathrm{CS}, \mathrm{US})$ & 0.0 & 0.0 & 1.0 & 0.0 \\
\hline (CS,US,VS) & 0.0 & 0.0 & 0.8 & 10 \\
\hline (CS,US,S) & 0.0 & 0.0 & 0.8 & 1.0 \\
\hline (CS,US,CS) & 0.0 & 0.0 & 0.8 & 1.0 \\
\hline (CS,US,US) & 0.0 & 0.0 & 0.8 & 1.0 \\
\hline ( US,VS,VS) & 0.0 & 0.4 & 1.0 & 0.8 \\
\hline ( US,VS,S ) & 0.0 & 0.2 & 1.0 & 0.8 \\
\hline ( US, VS,CS) & 0.0 & 0.2 & 0.8 & 1.0 \\
\hline ( US, VS, US ) & 0.0 & 0.2 & 0.8 & 1.0 \\
\hline ( US,S,VS) & 0.0 & 0.2 & 0.5 & 0.8 \\
\hline (US,S,S) & 0.0 & 0.5 & 0.8 & 0.6 \\
\hline ( US,S,CS ) & 0.0 & 0.2 & 1.0 & 0.8 \\
\hline ( US,S,US) & 0.0 & 0.2 & 0.8 & 1.0 \\
\hline ( US,CS,VS) & 0.0 & 0.2 & 1.0 & 0.8 \\
\hline ( US,CS,S ) & 0.0 & 0.2 & 1.0 & 0.8 \\
\hline ( US, CS,CS) & 0.0 & 0.2 & 1.0 & 0.8 \\
\hline
\end{tabular}




\begin{tabular}{|c|c|c|c|c|}
\hline ( US,CS,US) & 0.0 & 0.2 & 1.0 & 0.8 \\
\hline ( US,US,VS) & 0.0 & 0.0 & 0.0 & 1.0 \\
\hline ( US, US,S ) & 0.0 & 0.0 & 0.0 & 1.0 \\
\hline ( US,US,CS ) & 0.0 & 0.0 & 0.0 & 1.0 \\
\hline ( US,US,US ) & 0.0 & 0.0 & 0.0 & 1.0 \\
\hline
\end{tabular}




\section{APPENDIX - C}

Data used for the rulebase formation for the monitoring stage of the New England 39 bus system

Table. C1 Data used for the rulebase formation

\begin{tabular}{|c|c|c|c|c|}
\hline $\begin{array}{l}\text { Case } \\
\text { No }\end{array}$ & $\begin{array}{c}\text { Total Load at Selected } \\
\text { Buses ( MW ) }\end{array}$ & $\begin{array}{c}\text { Gen } 32 \\
\text { Volt ( p.u ) }\end{array}$ & $\begin{array}{c}\text { Bus } 12 \text { Load Volt } \\
\text { (p.u) }\end{array}$ & $\begin{array}{l}\text { Gen } 32 \\
\text { MVAR }\end{array}$ \\
\hline \multicolumn{5}{|c|}{ NO CONTINGENCY } \\
\hline 1 & $\begin{array}{l}1624.5 \\
3824.5 \\
4972.1\end{array}$ & $\begin{array}{l}0.9831 \\
0.9831 \\
0.9831\end{array}$ & $\begin{array}{l}0.9978 \\
0.8488 \\
0.6077\end{array}$ & $\begin{array}{l}9786.2 \\
9130.9 \\
8045.8\end{array}$ \\
\hline 2 & $\begin{array}{l}3624.5 \\
4824.5\end{array}$ & $\begin{array}{l}0.95 \\
0.95\end{array}$ & $\begin{array}{l}0.8478 \\
0.6325\end{array}$ & $\begin{array}{l}9290.9 \\
8330.0\end{array}$ \\
\hline 3 & $\begin{array}{l}1624.5 \\
4624.5 \\
5190.1\end{array}$ & $\begin{array}{l}1.05 \\
1.05 \\
1.05\end{array}$ & $\begin{array}{l}1.0285 \\
0.7986 \\
0.6273\end{array}$ & $\begin{array}{l}9594.1 \\
8530.3 \\
7740.0\end{array}$ \\
\hline & & CONTINGE & $\overline{V C Y}$ & \\
\hline 4 & $\begin{array}{l}1624.5 \\
4252.6\end{array}$ & $\begin{array}{l}0.9831 \\
0.9831\end{array}$ & $\begin{array}{l}0.9929 \\
0.6103\end{array}$ & $\begin{array}{l}9765.7 \\
8120.5\end{array}$ \\
\hline 5 & $\begin{array}{l}1624.5 \\
4099.5\end{array}$ & $\begin{array}{l}0.9831 \\
0.9831\end{array}$ & $\begin{array}{l}0.9896 \\
0.6758\end{array}$ & $\begin{array}{l}9752.8 \\
8400.0\end{array}$ \\
\hline 6 & $\begin{array}{l}1824.5 \\
3224.5 \\
4437.0\end{array}$ & $\begin{array}{l}0.9831 \\
0.9831 \\
0.9831\end{array}$ & $\begin{array}{l}0.9755 \\
0.8786 \\
0.6882\end{array}$ & $\begin{array}{l}9695.7 \\
9278.2 \\
8427.5\end{array}$ \\
\hline
\end{tabular}




\section{APPENDIX - D}

\section{Complete list of expert system output for the monitoring stage of the New England 39 bus system}

Table. D1 Expert system output for various neighborhood points Monitoring stage

\begin{tabular}{|c|c|c|c|c|c|c|c|}
\hline $\begin{array}{l}\text { Index } \\
\text { No }\end{array}$ & $\begin{array}{l}\text { Total Load at } \\
\text { Selected } \\
\text { Buses ( MW ) }\end{array}$ & $\begin{array}{l}\text { Gen } 32 \\
\text { Volt } \\
\text { (p.u) }\end{array}$ & $\begin{array}{l}\text { Bus } 12 \\
\text { Load Volt } \\
\text { (p.u) }\end{array}$ & $\begin{array}{l}\text { Gen } 32 \\
\text { MVAR }\end{array}$ & $\begin{array}{l}\text { Global } \\
\text { State }\end{array}$ & $\begin{array}{l}\text { VSTAI } \\
\text { Eigen } \\
\text { value }\end{array}$ & $\begin{array}{l}\text { output } \\
\text { System } \\
\text { State }\end{array}$ \\
\hline \multicolumn{8}{|c|}{ NO CONTINGENCY } \\
\hline 1 & 1424.5 & 0.9831 & 1.0072 & 9823.0 & VS & 10.11 & VS \\
\hline 2 & 1824.5 & 0.9831 & 0.9879 & 9746.5 & $\mathrm{~S}$ & 9.63 & $\mathrm{~S}$ \\
\hline 3 & 2624.5 & 0.9831 & 0.9428 & 9556.6 & $\mathrm{~S}$ & 8.50 & $\mathrm{~S}$ \\
\hline 4 & 4624.5 & 0.9831 & 0.7399 & 8628.3 & $\mathrm{CS}$ & 3.40 & CS \\
\hline 5 & 4958.8 & 0.9831 & 0.6250 & 8119.3 & US & 0.76 & US \\
\hline 6 & 4968.2 & 0.9831 & 0.6141 & 8073.1 & US & 0.52 & US \\
\hline 7 & 4971.4 & 0.9831 & 0.6093 & 8052.4 & US & 0.39 & US \\
\hline 8 & 3824.5 & 0.95 & 0.8276 & 9199.7 & CS & 5.77 & $\mathrm{CS}$ \\
\hline 9 & 4774.5 & 0.95 & 0.6580 & 8439.0 & US & 1.71 & US \\
\hline 10 & 4812.0 & 0.95 & 0.6399 & 8361.4 & US & 1.30 & US \\
\hline 11 & 1424.5 & 1.05 & 1.0374 & 9630.3 & VS & 10.55 & VS \\
\hline 12 & 1824.5 & 1.05 & 1.0190 & 9554.9 & VS & 10.09 & VS \\
\hline 13 & 4424.5 & 1.05 & 0.8263 & 8663.0 & $\mathrm{CS}$ & 5.10 & $\mathrm{CS}$ \\
\hline 14 & 4824.5 & 1.05 & 0.7644 & 8367.8 & $\mathrm{CS}$ & 3.55 & $\mathrm{CS}$ \\
\hline 15 & 5124.5 & 1.05 & 0.6801 & 7976.0 & US & 1.53 & US \\
\hline 16 & 5174.5 & 1.05 & 0.6482 & 7832.3 & US & 0.79 & US \\
\hline 17 & 5183.8 & 1.05 & 0.6378 & 7786.4 & US & 0.56 & US \\
\hline \multicolumn{8}{|c|}{ CONTINGENCY } \\
\hline 18 & 1424.5 & 0.9831 & 1.0041 & 9810.1 & $\mathrm{~S}$ & 9.89 & $\mathrm{~S}$ \\
\hline
\end{tabular}




\begin{tabular}{|c|c|c|c|c|c|c|c|}
\hline 19 & 1824.5 & 0.9831 & 0.9808 & 9717.2 & S & 9.32 & S \\
\hline 20 & 2224.5 & 0.9831 & 0.9542 & 9607.7 & S & 8.66 & S \\
\hline 21 & 3224.5 & 0.9831 & 0.8656 & 9223.9 & CS & 6.43 & CS \\
\hline 22 & 4187.0 & 0.9831 & 0.6755 & 8392.8 & US & 1.69 & US \\
\hline 23 & 1424.5 & 0.9831 & 0.9963 & 9778.3 & S & 9.04 & S \\
\hline 24 & 1624.5 & 0.9831 & 0.9862 & 9738.5 & S & 8.81 & S \\
\hline 25 & 2224.5 & 0.9831 & 0.9523 & 9599.9 & S & 8.01 & S \\
\hline 26 & 36245 & 0.9831 & 0.8385 & 9096.9 & CS & 5.21 & CS \\
\hline 27 & 4449.5 & 0.9831 & 0.6827 & 8403.6 & US & 1.40 & US \\
\hline 28 & 4462.0 & 0.9831 & 0.6762 & 8375.7 & US & 1.25 & US \\
\hline 29 & 1824.5 & 0.9831 & 0.9775 & 9703.9 & S & 8.47 & S \\
\hline 30 & 2224.5 & 0.9831 & 0.9506 & 9593.0 & S & 7.86 & S \\
\hline 31 & 3024.5 & 0.9831 & 0.8815 & 9294.9 & CS & 6.25 & CS \\
\hline 32 & 3224.5 & 0.9831 & 0.8594 & 9198.5 & CS & 5.73 & CS \\
\hline
\end{tabular}




\section{APPENDIX - E \\ Participation factors for the critical case}

( at the voltage stability limit ) of the New England 39 bus system

Table. E1 Bus and Generator participation factors for critical case

\begin{tabular}{|c|c|c|c|}
\hline \multicolumn{2}{|c|}{ Bus Participation Factors } & \multicolumn{2}{|c|}{ Generator Participation Factors } \\
\hline Bus No & Participation Factors & Gen No & Participation Factors \\
\hline \multicolumn{4}{|c|}{ Case 1} \\
\hline 12 & 0.1713 & 32 & 1.0000 \\
\hline 4 & 0.1042 & 31 & 0.7317 \\
\hline 14 & 0.0949 & & \\
\hline \multicolumn{4}{|c|}{ Case 2} \\
\hline 12 & 0.1788 & 32 & 1.0000 \\
\hline 4 & 0.1015 & 31 & 0.7390 \\
\hline 14 & 0.0941 & & \\
\hline \multicolumn{4}{|c|}{ Case 3} \\
\hline 12 & 0.1562 & 32 & 1.0000 \\
\hline 4 & 0.1093 & 31 & 0.7150 \\
\hline 14 & 0.0965 & & \\
\hline 13 & 0.0795 & & \\
\hline \multicolumn{4}{|c|}{ Case 4} \\
\hline 12 & 0.2469 & 32 & 1.0000 \\
\hline 13 & 0.1391 & & \\
\hline \multicolumn{4}{|c|}{ Case 5} \\
\hline 12 & 0.1436 & 32 & 1.0000 \\
\hline 4 & 0.1017 & 31 & 0.9206 \\
\hline 14 & 0.0932 & & \\
\hline 13 & 0.0811 & & \\
\hline 5 & 0.0753 & & \\
\hline \multicolumn{4}{|c|}{ Case 6} \\
\hline 12 & 0.2105 & 32 & 1.0000 \\
\hline 13 & 0.1247 & 31 & 0.5947 \\
\hline 14 & 0.1173 & & \\
\hline
\end{tabular}





